\title{
Is Implied Correlation Worth Calculating? Evidence from Foreign Exchange Options and Historical Data
}

\author{
Christian Walter \\ Economic Division \\ Swiss National Bank \\ Boersenstrasse 15 \\ CH-8022 Zurich \\ Phone: (011) 4116313573 \\ Fax: (011) 4116313980 \\ walter.christian@ snb.ch
}

\author{
Jose A. Lopez \\ Economic Research Department \\ Federal Reserve Bank of San Francisco \\ 101 Market Street \\ San Francisco, CA 94105 \\ Phone: (415) 977-3894 \\ Fax: (415) 974-2168 \\ jose.a..lopez@sf.frb.org
}

Draft date: May 2, 2000

\begin{abstract}
:
Implied volatilities, as derived from option prices, have been shown to be useful in forecasting the subsequently observed volatility of the underlying financial variables. In this paper, we address the question of whether implied correlations, derived from options on the exchange rates in a currency trio, are useful in forecasting the observed correlations. We compare the forecast performance of the implied correlations from two currency trios with markedly different characteristics against correlation forecasts based on historical, time-series data. For the correlations in the USD/DEM/JPY currency trio, we find that implied correlations are useful in forecasting observed correlations, but they do not fully incorporate all the information in the historical data. For the correlations in the USD/DEM/CHF currency trio, implied correlations are much less useful. In general, since the performance of implied correlations varies across currency trios, implied correlations may not be worth calculating in all instances.
\end{abstract}

Key Words: Implied correlation, Option prices, GARCH, Volatility forecasting JEL Categories: G13, F31, C53

Acknowledgements: The views expressed here are those of the authors and not necessarily those of the Swiss National Bank, the Federal Reserve Bank of San Francisco or the Federal Reserve System. We thank Allan Malz, John Zerolis and seminar participants at the Federal Reserve Bank of New York, the 1997 Latin American meeting of the Econometric Society, the 1998 Derivative Securities Conference and the 1998 meeting of the Western Finance Association for comments. We also thank Tae Kim for research assistance. This paper was written while the first author was on leave at the Federal Reserve Bank of New York. 


\title{
Is Implied Correlation Worth Calculating? Evidence from Foreign Exchange Options and Historical Data
}

\begin{abstract}
:
Implied volatilities, as derived from option prices, have been shown to be useful in forecasting the subsequently observed volatility of the underlying financial variables. In this paper, we address the question of whether implied correlations, derived from options on the exchange rates in a currency trio, are useful in forecasting the observed correlations. We compare the forecast performance of the implied correlations from two currency trios with markedly different characteristics against correlation forecasts based on historical, time-series data. For the correlations in the USD/DEM/JPY currency trio, we find that implied correlations are useful in forecasting observed correlations, but they do not fully incorporate all the information in the historical data. For the correlations in the USD/DEM/CHF currency trio, implied correlations are much less useful. In general, since the performance of implied correlations varies across currency trios, implied correlations may not be worth calculating in all instances.
\end{abstract}

Key Words: Implied correlation, Option prices, GARCH, Volatility forecasting JEL Categories: G13, F31, C53 


\section{Introduction}

The correlation between financial variables has emerged over the past few years as an important topic of financial research and practice. In the academic literature, several studies have examined the correlation between financial variables within an asset class; for example, see Bollerslev and Engle (1993) as well as Campa and Chang (1997) for foreign exchange rates, and Longin and Solnik (1995) as well as Karloyi and Stultz (1996) for equity indices. Bollerslev, Engle and Wooldridge (1988) examine the correlation across asset classes by modeling the covariance between stocks and Treasury securities. In actual practice, much work has been done

and is well exemplified by the variance-covariance matrix used in the well-known RiskMetrics ${ }^{\mathrm{TM}}$ calculations; see J.P. Morgan (1996) for further details. In addition, derivative contracts based on several financial variables at once have become more widely used in the 1990's, as surveyed by Mahoney (1995).

Most models of correlation use just past observed values of the variables in question as the relevant information set. However, another possible source of information for modeling correlation is derivative contracts; specifically, the implied correlations that can be derived from option prices. Implied correlation is defined as the measure of comovement between two variables as implied by the price of a single option contract or the prices of a combination of option contracts. Since option prices are "forward-looking" financial indicators that incorporate market expectations over the maturity of the option, they may provide interesting additional information not contained in the historical data. For example, Jorion (1995) found that implied volatilities derived from foreign exchange options outperform standard time-series models.

In this paper, we analyze the predictive ability of implied correlations between certain foreign exchange (FX) rates, as done by Bodurtha and Shen (1995), Siegel (1997) and Campa and Chang (1997). We complement and extend these studies in three ways. First, all three implied correlations extractable from options on the exchange rates in the currency trio of the US dollar (USD), the German mark (DEM), and the Japanese yen (JPY) are analyzed. We examine implied correlations with maturities of one and three months. Second, the three implied correlations extractable from options on the currency trio consisting of USD, DEM and the Swiss franc $(\mathrm{CHF})$, which has a markedly different correlation structure, are analyzed. Third, we 
compare the implied correlations against a larger set of alternative, time-series forecasts.

We find that the forecasting performance of implied correlations varies across the two currency trios. In all cases, implied correlations are biased forecasts, as found by Jorion (1995) for implied volatilities. For the USD/DEM/JPY trio, these forecasts outperform simple timeseries forecasts, such as historical correlations, in terms of having a lower root-mean-squared error. However, this result is not found for the USD/DEM/CHF trio. Using encompassing regressions, we generally reject the null hypothesis that implied correlations fully incorporate all the information available in the historical data. Specifically, we find for both currency trios that implied correlations frequently are encompassed by GARCH-based correlation forecasts, and in cases when this is not so, other time-series forecasts do incrementally provide useful information. This result suggests that the implied correlations either do not incorporate all the information in the price history or are based on a misspecified option pricing model.

In conclusion, the differences in our empirical results indicate that the value of implied correlations as predictors of future realized correlations is an empirical question. Performance is not uniform across the currency trios examined or across subperiods. Further research is necessary to determine the causes of this result, such as misspecification of the option pricing model or issues of market liquidity. Our argument is presented as follows. Section II introduces the concept of implied correlation and reviews the literature to date. Section III describes the data, the method used to obtain the implied correlations, and the alternative, time-series forecasts

used. Section IV presents the forecast evaluation results for implied correlation and the various time-series forecasts. Section V summarizes and concludes.

\section{Implied Correlation}

\section{a. From Implied Volatility to Implied Correlation}

Option pricing formulas relate the price of an option to the variables that influence its price. The famous Black-Scholes formula, for example, expresses the price of a European option on a non-dividend paying stock as a function of five variables: the option's strike price, its time to expiration, the risk-free interest rate, the price of the underlying asset, and the asset's volatility over the remaining life of the option. Since the first four variables and the option price are 
directly observable, one can invert the pricing formula, which is a monotonically increasing function of volatility, to determine the underlying asset's volatility as implied by the option price. This "implied" volatility is often interpreted as the market's assessment of the underlying asset's volatility over the remaining life of the option. ${ }^{1}$ Implied volatilities can be inferred from options on other assets as well. For FX options, the option pricing formula used to generate the implied volatilities is the Garman-Kohlhagen model (Garman and Kohlhagen, 1983), which modifies the Black-Scholes model to account for foreign interest rates. ${ }^{2}$

Implied volatilities can be viewed as forecasts of the volatility of the asset price over the maturity of the option. Although such forecasts can be easily generated by standard time-series models, implied volatilities are particularly useful because they are "forward-looking" economic indicators; i.e., they incorporate the market's expectations over future outcomes into the current price. An interesting question is whether forecasts of volatility should be based on implied volatilities, time-series models or some combination. Numerous researchers have addressed this question; see Mayhew (1995) for a survey. Currently, the literature suggests that implied volatility does generally forecast volatility better than simple time-series forecasts, such as historical volatility. However, more recent research, such as Kroner, Kneafsey and Claessens (1995) as well as Amin and $\mathrm{Ng}$ (1997), indicate that forecasts based on GARCH models contain information that does not seem to be present in implied volatilities. Both of these studies propose methods for combining these two types of volatility forecasts.

In this paper, we address this question for correlation forecasts. The topic of implied correlation, defined as the correlation between two variables as implied by the price of a single option or the prices of several options, has not received a comparable amount of attention, which

1 Note that the almost universal acceptance of a pricing formula by an options market neither implies the correctness of its assumptions nor the acceptance of these assumptions by market participants. It is simply a market convention for quoting prices. Deviations from the formula's assumptions are commonly accounted for by adjusting the quoted implied volatility.

2 In practice, extracting a single implied volatility for an asset is not so straightforward. Often, many options with identical times to expiration are written on the same asset, and their implied volatilities vary according to the characteristics of the options (i.e., strike price, the type of option, etc). Various weighting schemes have been developed to address this common problem; see Mayhew (1995). In this paper, only at-the-money implied volatilities are used. 
is surprising given the practical benefits of improving correlation forecasts. For example, investors optimizing portfolios in a mean-variance framework and risk managers calculating value-at-risk estimates need ex ante estimates of the variance-covariance matrix of asset returns over the relevant holding period. Better ex ante forecasts of this matrix should result in better financial decisions ex post.

A necessary condition for the extraction of implied correlation is the existence of derivatives whose prices are related to the level of correlation between two variables. In our case, options on the exchange rates in currency trios are commonly traded. Thus, one can infer the implied correlation between two exchange rates from the quoted implied volatilities as follows. Let $\mathrm{Y}_{\mathrm{A} / \mathrm{B}, \mathrm{t}+1}$ represent the daily exchange rate between currencies $\mathrm{A}$ and $\mathrm{B}$ at time $\mathrm{t}+1$, and let $\mathrm{y}_{\mathrm{A} / \mathrm{B}, \mathrm{t}+1}=\ln \left(\mathrm{Y}_{\mathrm{A} / \mathrm{B}, \mathrm{t}+1}\right)$. In terms of a third currency $\mathrm{C}$ and in the absence of arbitrage, clearly $\mathrm{Y}_{\mathrm{A} / \mathrm{B}, \mathrm{t}+1}=\mathrm{Y}_{\mathrm{A} / \mathrm{C}, \mathrm{t}+1} / \mathrm{Y}_{\mathrm{B} / \mathrm{C}, \mathrm{t}+1}$ and $\mathrm{y}_{\mathrm{A} / \mathrm{B}, \mathrm{t}+1}=\mathrm{y}_{\mathrm{A} / \mathrm{C}, \mathrm{t}+1}-\mathrm{y}_{\mathrm{B} / \mathrm{C}, \mathrm{t}+1}$. Since exchange rates are commonly found to be nonstationary, we focus our analysis on the log, differenced series; i.e., $\varepsilon_{\mathrm{A} / \mathrm{B}, \mathrm{t}+1}=\Delta \mathrm{y}_{\mathrm{A} / \mathrm{B}, \mathrm{t}+1}$ or, equivalently, $\varepsilon_{\mathrm{A} / \mathrm{B}, \mathrm{t}+1}=\varepsilon_{\mathrm{A} / \mathrm{C}, \mathrm{t}+1}-\varepsilon_{\mathrm{B} / \mathrm{C}, \mathrm{t}+1}$.

The unconditional variance of this series is simply

$$
\operatorname{Var}\left(\varepsilon_{\mathrm{A} / \mathrm{B}}\right)=\operatorname{Var}\left(\varepsilon_{\mathrm{A} / \mathrm{C}}\right)+\operatorname{Var}\left(\varepsilon_{\mathrm{B} / \mathrm{C}}\right)-2 \rho\left(\varepsilon_{\mathrm{A} / \mathrm{C}}, \varepsilon_{\mathrm{B} / \mathrm{C}}\right) \operatorname{Var}\left(\varepsilon_{\mathrm{A} / \mathrm{C}}\right)^{\frac{1}{2}} \operatorname{Var}\left(\varepsilon_{\mathrm{B} / \mathrm{C}}\right)^{\frac{1}{2}} .
$$

However, since exchange rates generally exhibit some form of time-dependent heteroskedasticity, the conditional variance at time $\mathrm{t}$ for a T-day horizon should be denoted

$$
\operatorname{Var}\left(\varepsilon_{\mathrm{A} / \mathrm{B}}\right)_{\mathrm{t}, \mathrm{T}}=\operatorname{Var}\left(\varepsilon_{\mathrm{A} / \mathrm{C}}\right)_{\mathrm{t}, \mathrm{T}}+\operatorname{Var}\left(\varepsilon_{\mathrm{B} / \mathrm{C}}\right)_{\mathrm{t}, \mathrm{T}}-2 \rho\left(\varepsilon_{\mathrm{A} / \mathrm{C}}, \varepsilon_{\mathrm{B} / \mathrm{C}}\right)_{\mathrm{t}, \mathrm{T}} \operatorname{Var}\left(\varepsilon_{\mathrm{A} / \mathrm{C}}\right)_{\mathrm{t}, \mathrm{T}}^{\frac{1}{2}} \operatorname{Var}\left(\varepsilon_{\mathrm{B} / \mathrm{C}}\right)_{\mathrm{t}, \mathrm{T}}^{\frac{1}{2}} .
$$

Thus, the conditional correlation at time $\mathrm{t}$ for a T-day horizon between the series $\varepsilon_{\mathrm{A} / \mathrm{C}, t+1}$ and $\varepsilon_{\mathrm{B} / \mathrm{C}, t+1}$ is denoted

$$
\rho\left(\varepsilon_{\mathrm{A} / \mathrm{C}}, \varepsilon_{\mathrm{B} / \mathrm{C}}\right)_{\mathrm{t}, \mathrm{T}}=\frac{\operatorname{Var}\left(\varepsilon_{\mathrm{A} / \mathrm{C}}\right)_{\mathrm{t}, \mathrm{T}}+\operatorname{Var}\left(\varepsilon_{\mathrm{B} / \mathrm{C}}\right)_{\mathrm{t}, \mathrm{T}}-\operatorname{Var}\left(\varepsilon_{\mathrm{A} / \mathrm{B}}\right)_{\mathrm{t}, \mathrm{T}}}{2 \operatorname{Var}\left(\varepsilon_{\mathrm{A} / \mathrm{C}}\right)_{\mathrm{t}, \mathrm{T}}^{\frac{1}{2}} \operatorname{Var}\left(\varepsilon_{\mathrm{B} / \mathrm{C}}\right)_{t, \mathrm{~T}}^{\frac{1}{2}}}
$$

which is purely a function of the conditional variances of the three series. The implied correlation between $\varepsilon_{\mathrm{A} / \mathrm{C}, \mathrm{t}+1}$ and $\varepsilon_{\mathrm{B} / \mathrm{C}, \mathrm{t}+1}$ over the next T-day horizon, denoted as $\hat{\rho}_{\mathrm{IV}}\left(\varepsilon_{\mathrm{A} / \mathrm{C}}, \varepsilon_{\mathrm{B} / \mathrm{C}}\right)_{\mathrm{t}, \mathrm{T}}$, is then simply a function of the implied volatilities from options with $\mathrm{T}$ days to maturity, denoted 
$\hat{\operatorname{Var}}_{\mathrm{IV}}(\mathrm{x})_{\mathrm{t}, \mathrm{T}} \dot{ }^{3}$ i.e.,

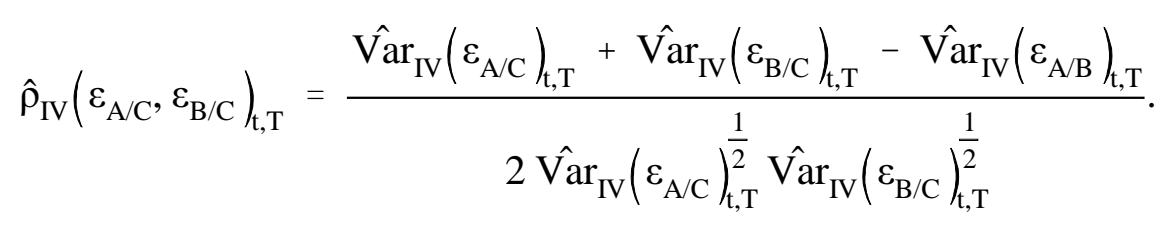

Note that any of the three currencies could serve as a base currency and that $\hat{\rho}_{\mathrm{IV}}\left(\varepsilon_{\mathrm{A} / \mathrm{B}}, \varepsilon_{\mathrm{C} / \mathrm{B}}\right)_{\mathrm{t}, \mathrm{T}}$ and $\hat{\rho}_{\mathrm{IV}}\left(\varepsilon_{\mathrm{B} / \mathrm{A}}, \varepsilon_{\mathrm{C} / \mathrm{A}}\right)_{\mathrm{t}, \mathrm{T}}$ would be formed analogously. ${ }^{4}$

\section{b. Literature review}

To date, implied correlation between FX rates has been the subject of studies by Bodurtha and Shen (1995); Siegel (1997); and Campa and Chang (1997). ${ }^{5}$ Bodurtha and Shen (1995) use options price data from the Philadelphia Stock Exchange to examine $\hat{\rho}_{\mathrm{IV}}\left(\varepsilon_{\mathrm{DEM} / \mathrm{USD}}, \varepsilon_{\mathrm{JPY} / \mathrm{USD}}\right)_{\mathrm{t}, \mathrm{T}}$, the implied correlation between $\varepsilon_{\mathrm{DEM} / \mathrm{USD}}$ and $\varepsilon_{\mathrm{JPY} / \mathrm{USD}}$. They evaluate the forecasting ability of implied correlation by regressing the observed, one-month correlations on one-month, implied correlations and several time-series correlation forecasts. They find that both historical and implied correlations provide useful information in forecasting realized correlation.

Siegel (1997) analyzes the forecasting performance of implied correlation in the context of a specific application; i.e., whether implied correlations improve the performance of crosscurrency hedges. Again, using options data from the Philadelphia Stock Exchange on two currency trios (the USD/DEM/JPY trio and the trio consisting of USD, DEM and the British pound), options-based hedge ratios for several currency positions were constructed. The volatilities of these hedged positions were then compared with the volatilities of hedged positions based on simple, time-series correlation forecasts. Siegel finds that the hedges based on implied

3 Note that option prices are stated in units of implied volatilities, which are really standard deviations. The common practice for converting these implied standard deviations into variances is simply to square them.

4 Note that the three implied correlations in a currency trio are not independent of each other. See Singer, Terhaar and Zerolis (1998) for a discussion of the geometric relationship between the volatilities and the correlations in a currency trio.

5 Gibson and Boyer (1997) examine the use of correlations in an option-trading exercise in order to compare alternative correlation forecasts. However, they do not use implied correlations in their study. 
correlations perform significantly better in some cases and never significantly worse than the time-series hedges. Furthermore, regression results indicate that the hedge ratios based on historical correlations provide no additional information beyond that already reflected in the hedge ratios based on implied correlations.

Unlike these two papers, Campa and Chang (1997) use data from the over-the-counter (OTC) market for FX options, which has three important advantages. First, since the OTC market for FX options is larger and more liquid than the market for these exchange-traded options, the OTC prices should be more informative than those from the Philadelphia Stock Exchange. ${ }^{6}$ Second, in contrast to exchange-traded options that have specific expiration dates, OTC options are issued daily with fixed times to maturity, which eliminates the need to adjust the implied volatilities for the effects of the options' time decay. Third, OTC options are generally created with at-the-money, strike prices. Since the sensitivity of options with regard to the underlying's volatility (the so-called "vega") is typically highest for at-the-money options, OTC options data ensure that the most information about the expected volatility is captured in the quoted prices. Beckers (1981) provides evidence supporting this view, finding that implied volatilities from at-the-money options do as well in predicting future volatilities as weighted averages of implied volatilities from different options. The loss of information incurred by using only at-the-money options, as done here, should therefore be modest.

Campa and Chang (1997) also analyze the forecasting ability of $\hat{\rho}_{\mathrm{IV}}\left(\varepsilon_{\mathrm{DEM} / \mathrm{USD}}, \varepsilon_{\mathrm{JPY} / \mathrm{USD}}\right)_{\mathrm{t}, \mathrm{T}}$. Their study is based on six and a half years of daily data on the implied volatilities of OTC options with constant times-to-maturity of one month and three months. As alternative forecasts to implied correlation, they consider simple, time-series forecasts as well as correlation forecasts generated by a rolling, bivariate $\operatorname{GARCH}(1,1)$ model. Applying a richer econometric methodology than the other two papers, they find that implied correlation outperforms the other forecasts. In particular, they find that none of the time-series forecasts are consistently capable of providing additional information relative to the implied correlation forecasts.

6 As shown by Cooper and Weston (1996), FX options are among the fastest-growing groups of OTC instruments and have become the subject of intense competition. As a consequence, their terms and conditions have been standardized, and the differences in competing quote prices have become relatively small (less than one percent of the average price). 
In summary, these studies provide some evidence on the forecasting ability of implied correlations. Given the potential benefits, we further analyze this forecasting ability by examining all three implied correlations extractable from the USD/DEM/JPY and USD/DEM/CHF trios, which have markedly different characteristics.

\section{Option Prices and Historical Data \\ a. Implied Correlations from Options Prices}

The options prices used in this paper were provided by a prominent bank dealing in the OTC market for FX options. The data consist of daily, one-month and three-month implied volatilities for the three currency pairs in a currency trio. For the USD/DEM/JPY trio, data from October 2, 1990 through April 2, 1997 (1679 observations) are available, and for the USD/DEM/CHF trio, data from September 13, 1993 through April 2, 1997 (910 observations) are available. We thus compare the forecast performance of twelve correlations (two currency trios with three correlations each for two forecast horizons).

The implied volatilities are for at-the-money forward straddles, a combination of a European call option and a European put option with the strike prices set at the forward rate. Although the implied volatilities are derived from the Garman-Kohlhagen pricing model, they are probably subject to model misspecification problems since this model assumes constant volatility. However, as per Hull and White (1987), the pricing impact of time-varying volatility should be small for options with less than one year to maturity. We thus do not correct the implied volatilities for the presence of this misspecification error.

Figure 1 depicts the implied correlations for the two currency trios, and Table 1 presents the corresponding summary statistics. Note that the two currency trios have markedly different correlation structures. The implied correlations for the USD/DEM/JPY (or yen) trio differ much less in their means and standard deviations than those for the USD/DEM/CHF (or franc) trio, as

clearly seen in the figure. Specifically, $\hat{\rho}_{\mathrm{IV}}\left(\varepsilon_{\mathrm{DEM} / \mathrm{USD}}, \varepsilon_{\mathrm{CHF} / \mathrm{USD}}\right)_{\mathrm{t}, \mathrm{T}}$ has a much higher mean and lower standard deviation than the other five correlations analyzed, which is indicative of the 
close economic relationship between Germany and Switzerland. ${ }^{7}$

\section{b. Realized Correlation}

Correlation, as with all higher moments of time-series data, is not directly observable. Thus, the realized correlation over a horizon of $\mathrm{T}$ days must be proxied for by a consistent, empirical estimate. In this case, the realized correlation between the log, differenced exchange rates $\varepsilon_{\mathrm{A} / \mathrm{C}, \mathrm{t}+1}$ and $\varepsilon_{\mathrm{B} / \mathrm{C}, \mathrm{t}+1}$ at time t over a T-day horizon is calculated as

$$
\rho\left(\varepsilon_{\mathrm{A} / \mathrm{C}}, \varepsilon_{\mathrm{B} / \mathrm{C}}\right)_{\mathrm{t}, \mathrm{T}}=\frac{\sum_{\mathrm{i}=1}^{\mathrm{T}}\left(\varepsilon_{\mathrm{A} / \mathrm{C}, \mathrm{t}+\mathrm{i}}-\hat{\mu}_{\mathrm{A} / \mathrm{C}}\right)\left(\varepsilon_{\mathrm{B} / \mathrm{C}, \mathrm{t}+\mathrm{i}}-\hat{\mu}_{\mathrm{B} / \mathrm{C}}\right)}{\sqrt{\sum_{\mathrm{i}=1}^{\mathrm{T}}\left(\varepsilon_{\mathrm{A} / \mathrm{C}, \mathrm{t}+\mathrm{i}}-\hat{\mu}_{\mathrm{A} / \mathrm{C}}\right)^{2}} \sqrt{\sum_{\mathrm{i}=1}^{\mathrm{T}}\left(\varepsilon_{\mathrm{B} / \mathrm{C}, \mathrm{t}+\mathrm{i}}-\hat{\mu}_{\mathrm{B} / \mathrm{C}}\right)^{2}}},
$$

where $\hat{\mu}_{\mathrm{A} / \mathrm{C}}$ and $\hat{\mu}_{\mathrm{B} / \mathrm{C}}$ are the corresponding sample means over the T-day period. The spot exchange rate data used to calculate the realized correlations (and the alternative correlation forecasts) is from the Swiss National Bank and consists of daily spot exchange rates from January 3, 1980 through July 2, 1997, which is the in-sample estimation period.

In this paper, we focus on the one-month and three-month horizons matching the options data. In the OTC market for FX options, the maturity of a contract is defined by calendar time; i.e., an n-month option started on the date $\mathrm{mm} / \mathrm{dd} / \mathrm{yy}$ expires on the date $\mathrm{mm}+\mathrm{n} / \mathrm{dd} / \mathrm{yy}$ if this day is a weekday or the next workday if it falls on a weekend. Hence, the option's time to maturity measured in days is variable, depending on the calendar month. For our data set, the effective number of trading days for the one-month horizon ranges from 18 to 23 with a mean of 21.9 and a standard deviation of 1.0. For the three-month horizon, the effective number of trading days ranges from 59 to 66 with a mean of 64.7 and a standard deviation of 1.4. In order to reduce measurement error in the realized and forecasted correlations, we allow the maturity of the option, as measured in days, to vary in our calculations.

${ }^{7}$ Note that Switzerland is not a member of the European Monetary System and that the Swiss franc is not linked to the German mark. Thus, there are no explicit, legally binding restrictions on these exchange rates. 


\section{c. Simple Correlation Forecasts}

The first category of time-series, correlation forecasts examined are based on rolling averages of the products of past exchange rate changes. We consider two approaches that differ only in the weights applied in the averages. Specifically, historical correlation equally weights all observations, and exponentially-weighted moving average (EWMA) correlation is based on weights that decline exponentially; i.e., $\mathrm{w}_{\mathrm{i}}=\lambda^{\mathrm{i}}$ for integer $\mathrm{i}>0$, where $\lambda$ is a calibrated parameter. Note that both methods assume that the correlation forecasts are independent of the forecast horizon; i.e., $\hat{\rho}_{\mathrm{m}}\left(\varepsilon_{\mathrm{A} / \mathrm{C}}, \varepsilon_{\mathrm{B} / \mathrm{C}}\right)_{\mathrm{t}, \mathrm{T}_{1}}=\hat{\rho}_{\mathrm{m}}\left(\varepsilon_{\mathrm{A} / \mathrm{C}}, \varepsilon_{\mathrm{B} / \mathrm{C}}\right)_{\mathrm{t}, \mathrm{T}_{2}}$, where the horizons $\mathrm{T}_{1}$ and $\mathrm{T}_{2}$ are not the same. Hence, these simple forecasts imply a flat term-structure of correlation.

\section{Historical Correlation}

The historical correlation forecast at time t for any forecast horizon is defined as the realized correlation over a fixed number of trading days prior to time $t$; i.e.,

$$
\hat{\rho}_{\mathrm{H}(\mathrm{n})}\left(\varepsilon_{\mathrm{A} / \mathrm{C}}, \varepsilon_{\mathrm{B} / \mathrm{C}}\right)_{\mathrm{t}}=\frac{\sum_{\mathrm{i}=1}^{\mathrm{n}}\left(\varepsilon_{\mathrm{A} / \mathrm{C}, \mathrm{t}-\mathrm{i}+1}-\hat{\mu}_{\mathrm{A} / \mathrm{C}}\right)\left(\varepsilon_{\mathrm{B} / \mathrm{C}, \mathrm{t}-\mathrm{i}+1}-\hat{\mu}_{\mathrm{B} / \mathrm{C}}\right)}{\sqrt{\sum_{\mathrm{i}=1}^{\mathrm{n}}\left(\varepsilon_{\mathrm{A} / \mathrm{C}, \mathrm{t}-\mathrm{i}+1}-\hat{\mu}_{\mathrm{A} / \mathrm{C}}\right)^{2}} \sqrt{\sum_{\mathrm{i}=1}^{\mathrm{n}}\left(\varepsilon_{\mathrm{B} / \mathrm{C}, \mathrm{t}-\mathrm{i}+1}-\hat{\mu}_{\mathrm{B} / \mathrm{C}}\right)^{2}}},
$$

where $\mathrm{n}$ denotes the number of trading days in the "observation period". Note that all $\mathrm{n}$ observations within the observation period are given equal weight, and all observations older than $\mathrm{n}$ days are given zero weight. Since there is no obvious way to select $\mathrm{n}$, we examine the performance of historical correlation forecasts based on 20,60 and 120 days of data or roughly one, three and six months, respectively.

\section{Exponentially-Weighted Moving Average Correlation}

The EWMA correlation forecast at time $\mathrm{t}$ for any forecast horizon is defined as

$$
\hat{\rho}_{\mathrm{E}(\lambda, \mathrm{k})}\left(\varepsilon_{\mathrm{A} / \mathrm{C}}, \varepsilon_{\mathrm{B} / \mathrm{C}}\right)_{\mathrm{t}}=\frac{\sum_{\mathrm{i}=0}^{\mathrm{k}} \lambda^{\mathrm{i}}\left(\varepsilon_{\mathrm{A} / \mathrm{C}, \mathrm{t}-\mathrm{i}}-\hat{\mu}_{\mathrm{A} / \mathrm{C}}\right)\left(\varepsilon_{\mathrm{B} / \mathrm{C}, \mathrm{t}-\mathrm{i}}-\hat{\mu}_{\mathrm{B} / \mathrm{C}}\right)}{\sqrt{\sum_{\mathrm{i}=0}^{\mathrm{k}} \lambda^{\mathrm{i}}\left(\varepsilon_{\mathrm{A} / \mathrm{C}, \mathrm{t}-\mathrm{i}}-\hat{\mu}_{\mathrm{A} / \mathrm{C}}\right)^{2}} \sqrt{\sum_{\mathrm{i}=0}^{\mathrm{k}} \lambda^{\mathrm{i}}\left(\varepsilon_{\mathrm{B} / \mathrm{C}, \mathrm{t}-\mathrm{i}}-\hat{\mu}_{\mathrm{B} / \mathrm{C}}\right)^{2}}},
$$


where $\lambda \in(0,1)$ is the decay factor and $\mathrm{k}$ is the number of historical observations used in the calculation. The EWMA approach, well known due to its use by J.P. Morgan's RiskMetrics ${ }^{\mathrm{TM}}$ system for forecasting variances and covariances, offers two advantages over the previous approach. First, by giving recent data more weight, the forecasts react faster to short-term movements in exchange rates. Second, by exponentially smoothing out the effect of a given rate change, EWMA forecasts do not exhibit the abrupt changes common to historical forecasts once such a change falls out of the observation period.

The decay factor $\lambda$ determines the relative weights applied to the observations; lower values of $\lambda$ imply faster rates of decay in the influence of a given observation. Following Hendricks (1996), we consider three different decay factors: $\lambda=0.94,0.97$, and 0.99 . We


Since $\mathrm{k}$ is constant, the three EWMA correlation forecasts are simply denoted $\mathrm{E}(0.94), \mathrm{E}(0.97)$, and $\mathrm{E}(0.99)$, respectively.

\section{d. Correlation Forecasts Based on a Bivariate GARCH(1,1) Model}

As developed by Engle (1982) and Bollerslev (1986), the univariate GARCH model has become an established method for characterizing the variance dynamics found in financial time series. In the bivariate GARCH model, the covariance also evolves over time and is specified in a manner similar to that in the univariate case. ${ }^{8}$ The basic structure of the model for $\varepsilon_{\mathrm{t}+1}=\left[\varepsilon_{\mathrm{A} / \mathrm{C}, \mathrm{t}+1}, \varepsilon_{\mathrm{B} / \mathrm{C}, \mathrm{t}+1}\right]=\left[\varepsilon_{1, \mathrm{t}+1}, \varepsilon_{2, \mathrm{t}+1}\right]$ is that the components of the conditional variancecovariance matrix $\mathrm{H}_{\mathrm{t}+1}$ vary through time as functions of the products of the observed innovations and past values of $\mathrm{H}_{\mathrm{t}+1}$. Specifically,

$$
\mathrm{H}_{\mathrm{t}+1}=\left[\begin{array}{ll}
\mathrm{h}_{11, \mathrm{t}+1} & \mathrm{~h}_{12, \mathrm{t}+1} \\
\mathrm{~h}_{12, \mathrm{t}+1} & \mathrm{~h}_{22, \mathrm{t}+1}
\end{array}\right]
$$

where $h_{11, t+1}$ and $h_{22, t+1}$ are the variances of the two series and $h_{12, t+1}$ is their covariance.

\footnotetext{
${ }^{8}$ For an overview of multivariate GARCH models, see Bollerslev, Engle, and Nelson (1994).
} 
A common specification of a bivariate Gaussian, GARCH process is that $\varepsilon_{\mathrm{t}+1} \mid \Omega_{\mathrm{t}} \sim \mathrm{N}\left(0, \mathrm{H}_{\mathrm{t}+1}\right)$, where

$$
\operatorname{vech}\left(H_{t+1}\right)=W+A \operatorname{vech}\left(\varepsilon_{t} \varepsilon_{t}\right)+B \operatorname{vech}\left(H_{t}\right)
$$

where vech $(\cdot)$ is the vector-half operator that converts $(\mathrm{N} \times \mathrm{N})$ matrices into $(\mathrm{N}(\mathrm{N}+1) / 2 \times 1)$

vectors of their lower triangular elements, $\mathrm{W}$ is a $(3 \times 1)$ parameter vector, and $\mathrm{A}$ and $\mathrm{B}$ are $(3 \times 3)$ parameter matrices. Alternatively, the model takes the matrix form,

$$
\left[\begin{array}{l}
h_{11, t+1} \\
h_{12, t+1} \\
h_{22, t+1}
\end{array}\right]=\left[\begin{array}{l}
\omega_{11} \\
\omega_{12} \\
\omega_{22}
\end{array}\right]+\left[\begin{array}{lll}
\alpha_{11} & \alpha_{12} & \alpha_{13} \\
\alpha_{21} & \alpha_{22} & \alpha_{23} \\
\alpha_{31} & \alpha_{32} & \alpha_{33}
\end{array}\right]\left[\begin{array}{c}
\varepsilon_{1, t}^{2} \\
\varepsilon_{1, t} \varepsilon_{2, t} \\
\varepsilon_{2, t}^{2}
\end{array}\right]+\left[\begin{array}{lll}
\beta_{11} & \beta_{12} & \beta_{13} \\
\beta_{21} & \beta_{22} & \beta_{23} \\
\beta_{31} & \beta_{32} & \beta_{33}
\end{array}\right]\left[\begin{array}{l}
h_{1, t} \\
h_{12, t} \\
h_{2, t}
\end{array}\right] .
$$

Given the model's 21 parameters, numerical maximization of the likelihood function is generally too cumbersome. To enforce parametric parsimony, we follow Bollerslev, Engle and Wooldridge (1988), who specify the A and B matrices to be diagonal and reduce the number of parameters to just 9 ; i.e.,

$$
\left[\begin{array}{l}
\mathrm{h}_{11, \mathrm{t}+1} \\
\mathrm{~h}_{12, \mathrm{t}+1} \\
\mathrm{~h}_{22, \mathrm{t}+1}
\end{array}\right]=\left[\begin{array}{l}
\omega_{11} \\
\omega_{12} \\
\omega_{22}
\end{array}\right]+\left[\begin{array}{lll}
\alpha_{11} & 0 & 0 \\
0 & \alpha_{12} & 0 \\
0 & 0 & \alpha_{22}
\end{array}\right]\left[\begin{array}{c}
\varepsilon_{1, \mathrm{t}}^{2} \\
\varepsilon_{1, \mathrm{t}} \varepsilon_{2, \mathrm{t}} \\
\varepsilon_{2, \mathrm{t}}^{2}
\end{array}\right]+\left[\begin{array}{lll}
\beta_{11} & 0 & 0 \\
0 & \beta_{12} & 0 \\
0 & 0 & \beta_{22}
\end{array}\right]\left[\begin{array}{l}
\mathrm{h}_{11, \mathrm{t}} \\
\mathrm{h}_{12, \mathrm{t}} \\
\mathrm{h}_{22, \mathrm{t}}
\end{array}\right],
$$

which implies that $\mathrm{h}_{\mathrm{ij}, \mathrm{t}+1}=\omega_{\mathrm{ij}}+\alpha_{\mathrm{ij}} \varepsilon_{\mathrm{i}, \mathrm{t}} \varepsilon_{\mathrm{j}, \mathrm{t}}+\beta_{\mathrm{ij}} \mathrm{h}_{\mathrm{ij}, \mathrm{t}}$ for $\mathrm{i}, \mathrm{j}=1,2$.

Table 2, Panels 1 and 2 present the estimated parameters for the bivariate $\operatorname{GARCH}(1,1)$ model over the entire in-sample period of January 3, 1980 through October 2, 1990. Since we forecast all the correlations in the two currency trios, we estimate this model for the six exchange rate pairs. Given that some studies, such as Hsieh (1989) and Bollerslev et. al. (1994), have found significant first-order autocorrelations in the logged, first differences of FX rates, we estimated the model's conditional mean with and without an MA(1) term. That is, the conditional mean is specified as $100 \Delta \mathrm{y}_{\mathrm{t}+1}=\mu+\theta \varepsilon_{\mathrm{t}}+\varepsilon_{\mathrm{t}+1}$, where $\mathrm{y}_{\mathrm{t}+1}=\left[\mathrm{y}_{\mathrm{A} / \mathrm{C}, \mathrm{t}+1} ; \mathrm{y}_{\mathrm{B} / \mathrm{C}, \mathrm{t}+1}\right]$ and $\theta$ is a diagonal matrix, and as $100 \Delta y_{t+1}=\mu+\varepsilon_{t+1}$, where the diagonal elements of $\theta$ are set to zero. Using the likelihood-ratio test, we find that the simpler specification cannot be rejected 
in favor of the MA(1) specification; see the $\mathrm{LR}_{\mathrm{MA}}$ statistics in Table 2. Based on this result, we use the simple conditional mean specification to generate the GARCH-based correlation forecasts. Note that these estimates, as often found in the literature, suggest considerable persistence since $\alpha_{\mathrm{ij}}+\beta_{\mathrm{ij}}$ is above 0.9 in all cases.

GARCH parameters derived from models estimated over the entire data sample obviously reflect all of that information. In order to avoid giving the GARCH-based correlation forecasts the advantage of ex post parameterization, we more closely approximate actual forecasting with "rolling GARCH" estimations using the 1000 observations prior to the date on which the forecast is made. Table 2, Panel $\mathrm{C}$ contains the parameter estimates for $\varepsilon_{\mathrm{DEM} / \mathrm{USD}}$ and $\varepsilon_{\mathrm{JPY} / \mathrm{USD}}$ for the 1000 datapoints before the first out-of-sample, forecasting date (October 2, 1990). The last three columns of the table report the mean, minimum and maximum parameter values, which indicate variation in the parameter estimates over time. Although the estimated parameters vary over time, they generally remain in small ranges that do not change the overall inference. Similar results are obtained for the other exchange rate pairs.

The correlation forecasts generated from a GARCH model are different from the forecasts generated by the simpler models in an important way. The previous models assume that the daily, FX variances and covariances are constant, and thus, a forecast of the T-day correlation is exactly equal to the past observed correlation. However, for the GARCH model, forecasts of $\mathrm{H}_{\mathrm{t}+1}$ change daily; the k-step-ahead forecast of $h_{i j}$ at time $t$ is

$$
E_{t}\left[h_{i j, t+k}\right]= \begin{cases}\omega_{i j}+\alpha_{i j} \varepsilon_{i j, t}+\beta_{i j} h_{i j, t} & \text { if } k=1 \\ \omega_{i j} \sum_{s=0}^{k-1}\left(\alpha_{i j}+\beta_{i j}\right)^{s}+\left(\alpha_{i j}+\beta_{i j}\right)^{k-1} E_{t}\left[h_{i j, t+1}\right] & \text { if } k>1 .\end{cases}
$$

Since the daily innovations are not serially correlated, the forecast at time $\mathrm{t}$ of an element of $\mathrm{H}_{\mathrm{t}+1}$ over the subsequent T-day period is equal to $\mathrm{E}_{\mathrm{t}}\left[\mathrm{h}_{\mathrm{ij}, \mathrm{t}, \mathrm{T}}\right]=\sum_{\mathrm{s}=1}^{\mathrm{T}} \mathrm{E}_{\mathrm{t}}\left[\mathrm{h}_{\mathrm{ij}, \mathrm{t}+\mathrm{s}}\right]$. The corresponding correlation forecast $\hat{\rho}_{\mathrm{G}}\left(\varepsilon_{\mathrm{A} / \mathrm{C}}, \varepsilon_{\mathrm{B} / \mathrm{C}}\right)_{\mathrm{t}, \mathrm{T}}$ is then

$$
\hat{\rho}_{\mathrm{G}}\left(\varepsilon_{\mathrm{A} / \mathrm{C}}, \varepsilon_{\mathrm{B} / \mathrm{C}}\right)_{\mathrm{t}, \mathrm{T}}=\frac{\mathrm{E}_{\mathrm{t}}\left[\mathrm{h}_{12, \mathrm{t}, \mathrm{T}}\right]}{\sqrt{\mathrm{E}_{\mathrm{t}}\left[\mathrm{h}_{11, \mathrm{t}, \mathrm{T}}\right] \sqrt{\mathrm{E}_{\mathrm{t}}\left[\mathrm{h}_{22, \mathrm{t}, \mathrm{T}}\right]}}} .
$$

Since we want to analyze the performance of the various correlation forecasts for two forecast 
horizons, the rolling GARCH parameter estimates for the six exchange rate pairs are used to generate the twelve GARCH-based correlation forecasts of interest. As with the realized correlation, we take account of the effective number of trading days of the option contract used to extract the corresponding implied correlation.

\section{Evaluating the Predictive Accuracy of the Correlation Forecasts}

Figure 2 illustrates some typical properties of the various forecasts. The graphs show the realized correlation $\rho\left(\varepsilon_{\mathrm{DEM} / \mathrm{USD}}, \varepsilon_{\mathrm{JPY} / \mathrm{USD}}\right)_{\mathrm{t}, \mathrm{T}}$ and the corresponding forecasts. Clearly, realized correlation is much more variable than both the implied and GARCH-based forecasts. The simple, time-series forecasts show the typical properties documented by Hendricks (1996). For historical correlation, the longer the observation period, the less variable the forecast. For the EWMA forecasts, the higher the decay factor, the longer the effective observation period and, consequently, the less variable the forecast.

In this section, we evaluate the predictive accuracy of the competing forecasts presented above using three types of forecast evaluation criteria. The first two criteria examine the properties of the individual forecasts themselves, and the third criteria examines their relative performance. Below, we describe the three criteria and report our empirical results.

\section{a. Three Types of Forecast Evaluation Criteria}

\section{Analysis of Forecast Errors}

The first type of evaluation criteria is based on the analysis of the forecast errors, defined

as $\mathrm{e}_{\mathrm{m}, \mathrm{t}}=\hat{\rho}_{\mathrm{m}}\left(\varepsilon_{\mathrm{A} / \mathrm{C}}, \varepsilon_{\mathrm{B} / \mathrm{C}}\right)_{\mathrm{t}, \mathrm{T}}-\rho\left(\varepsilon_{\mathrm{A} / \mathrm{C}}, \varepsilon_{\mathrm{B} / \mathrm{C}}\right)_{\mathrm{t}, \mathrm{T}}$, where $\hat{\rho}_{\mathrm{m}}(\cdot)_{\mathrm{t}, \mathrm{T}}$ is the forecast of the correlation at time $t$ generated by model $\mathrm{m}$. To evaluate the performance of the various forecasts, we calculate the mean forecast errors (MFEs) and the root-mean-squared forecast errors (RMSFEs). A standard property of optimal forecasts is that they are unbiased, which implies that the forecast errors have zero means. To test for this property, we regress $e_{m, t}$ on a constant using the Newey and West (1987) standard errors to account for unknown heteroskedasticity and autocorrelation. If that coefficient is significantly different from zero, then the forecast is said to be biased. 
We then compare the relative RMSFEs using the test proposed by Diebold and Mariano (1995). Taking root-mean-squared error as the relevant loss function, for a particular correlation, we generate the time series of the differences between the loss function values of each forecast and the best forecast in RMSFE terms. If two forecasts are equally accurate, then the mean of this difference should be zero. If we reject this null hypothesis, then the forecast with the lower RMSFE is truly the more accurate forecast. The asymptotic Diebold-Mariano statistic tests the hypothesis with what is essentially a t-statistic that this mean is zero.

\section{Partial Optimality Regressions}

The second type of evaluation criteria assesses the partial optimality of the various forecasts. Partial optimality refers to whether the forecast errors are unforecastable with respect to some subset of available information; see Brown and Maital (1981) as well as the discussion in Diebold and Lopez (1996). In our analysis, if a forecast is partially optimal, then the forecast error should be orthogonal to the forecast itself. Following Mincer and Zarnowitz (1969), we test for the partial optimality of the correlation forecasts by running regressions of the following type

$$
\rho(\cdot)_{\mathrm{t}, \mathrm{T}}=\mathrm{a}+\mathrm{b} \hat{\rho}_{\mathrm{m}}(\cdot)_{\mathrm{t}, \mathrm{T}}+\mathrm{v}_{\mathrm{t}}
$$

Partial optimality of a forecast corresponds to parameter estimates of $(a, b)$ that are insignificantly different from zero and one, respectively. Deviation from those parameter values is evidence that the forecast errors are not orthogonal to the forecasts themselves; i.e., if the forecast errors are correlated with the forecasts, the forecasts do not make optimal use of the data used to form them.

\section{Encompassing Regressions}

The third type of evaluation criteria uses multiple regression analysis to assess the information content of different forecasts. The so-called encompassing regressions enable us to determine whether a certain forecast incorporates (or encompasses) all the relevant information in competing forecasts; see Chong and Hendry (1986) for further discussion. To illustrate the idea, consider the case of two correlation forecasts, $\hat{\rho}_{1}(\cdot)_{\mathrm{t}, \mathrm{T}}$ and $\hat{\rho}_{2}(\cdot)_{\mathrm{t}, \mathrm{T}}$. If the regression 


$$
\rho(\cdot)_{\mathrm{t}, \mathrm{T}}=\gamma_{0}+\gamma_{1} \hat{\rho}_{1}(\cdot)_{\mathrm{t}, \mathrm{T}}+\gamma_{2} \hat{\rho}_{2}(\cdot)_{\mathrm{t}, \mathrm{T}}+v_{\mathrm{t}}
$$

results in parameter estimates $\left(\gamma_{0}, \gamma_{1}, \gamma_{2}\right)$ that are not significantly different from $(0,1,0)$, then forecast 1 is said to encompass forecast 2; i.e., the information set used to form forecast 1 encompasses that used to form forecast 2. Similarly, if the parameter estimates are not significantly different from $(0,0,1)$, forecast 2 encompasses forecast 1 . For any other values, neither model encompasses the other, and both forecasts contain useful information.

In order to test for the information contribution of the various forecasts, we estimate encompassing regressions for every correlation analyzed. Since the simple forecasts tend to be correlated among themselves, we do not include them all as right-hand variables. Instead, we include the two "sophisticated" forecasts of implied and GARCH-based correlation along with one historical and one EWMA forecast. We choose one each from among the historical and EWMA correlations according to the maximal $\mathrm{R}^{2} \mathrm{~s}$ from the partial optimality regressions.

\section{b. Empirical Results for the Various Correlation Forecasts}

\section{Analysis of Forecast Errors}

Table 3 reports the mean forecast errors (MFEs) and root-mean-squared forecast errors (RMSFEs) for both the one-month and three-month maturities of each currency trio. ${ }^{9}$ For both trios, the MFE results indicate that the sophisticated forecasts generally have larger forecast biases than the simple forecasts, and these biases are significant in 19 of 24 cases. The small MFEs of the simple correlation forecasts are not surprising, given that they approximate the unconditional correlation of the series using a subsample of the available data. However, the bias in the sophisticated forecasts is harder to explain, although Jorion (1995) found significant biases for implied volatility forecasts from FX options.

Yet, the reported RMSFE and Diebold-Mariano (D\&M) test results indicate that the

\footnotetext{
9 Note that the RMSFEs tend to be lower for the three-month correlations than for the one-month correlations, suggesting that correlation forecasts tend to be more accurate for longer forecast horizons, possibly reflecting reversion to the unconditional covariance over long time periods.
} 
unbiased nature of the simple forecasts does not imply that they necessarily have a closer relationship to the realized correlations. For the yen trio, the implied and GARCH-based forecasts generate the lowest RMSFEs in all six cases. (Note that the minimum RMSFE in each column is marked in bold.) Furthermore, the D\&M results indicate that these sophisticated forecasts are never significantly different than the forecast with the lowest RMSFE. Thus, the sophisticated forecasts perform quite well under the RMSFE criteria for this currency trio.

However, their performance for the franc trio is not as good. The implied and GARCHbased forecasts minimize RMSFE only once each among the six cases. Whereas implied correlation performs relatively well for $\rho\left(\varepsilon_{\mathrm{DEM} / \mathrm{USD}}, \varepsilon_{\mathrm{CHF} / \mathrm{USD}}\right)_{\mathrm{t}, \mathrm{T}}$, its performance with respect to the other two correlations is poor. ${ }^{10}$ Not only do the option-based forecasts for these two correlations exhibit RMSFEs that are significantly larger than the RMSFEs of the best respective forecasts, they also have MFEs (or bias) of an order of magnitude (going up to almost 0.3 in absolute size) that questions their usefulness in predicting these correlations. Note that the GARCH-based forecasts are never significantly different from the minimizing forecasts.

A clear conclusion that arises from these results is that the implied correlations are not uniformly the best forecasts of realized correlation. Although they perform well for the yen trio, their performance for the franc trio indicates that implied correlations may not always be the best forecast available and may not be worth calculating.

\section{Partial Optimality Regressions}

The results for the partial optimality regressions are reported in Table 4. For both trios, the simple forecasting methods consistently violate both conditions that a partially optimal forecast must fulfill; i.e., $(a, b)=(0,1)$. Only one of the 72 sets of such forecasts examined (i.e., one-month $\left.\hat{\rho}_{\mathrm{E}(0.90)}\left(\varepsilon_{\mathrm{USD} / \mathrm{JPY}}, \varepsilon_{\mathrm{DEM} / \mathrm{JPY}}\right)_{\mathrm{t}, \mathrm{T}}\right)$ is found to pass the individual tests for partial optimality, but not the joint test.

${ }^{10}$ Note the low variability of $\rho\left(\varepsilon_{\mathrm{DEM} / \mathrm{USD}}, \varepsilon_{\mathrm{CHF} / \mathrm{USD}}\right)_{\mathrm{LT}}$ is reflected in the relatively small size of the RMSFEs of its forecasts, which are about four to ten times smaller than those of the other correlations analyzed. Note further that there is a high degree of correspondence in the accuracy of the forecasts $\rho\left(\varepsilon_{\mathrm{USD} / \mathrm{DEM}}, \varepsilon_{\mathrm{CHF} / \mathrm{DEM}}\right)_{\mathrm{tT}}$ and $\rho\left(\varepsilon_{\mathrm{USD} / \mathrm{CHF}}, \varepsilon_{\mathrm{DEM} / \mathrm{CHF}}\right)_{\mathrm{tT}}$, due to the fact that the correlations in a currency trio are related. Given that $\rho\left(\varepsilon_{\mathrm{DEM} / \mathrm{USD}}, \varepsilon_{\mathrm{CHF} / \mathrm{USD}}\right)_{\mathrm{tT}}$ is relatively constant, the mutual dependency of the three correlations implies that the forecast errors for the other two correlations in this trio will be related in absolute size. 
With respect to the sophisticated forecasts, there are once again important differences in performance between the two currency trios. For the yen trio, these forecasts generally perform better. In eight out of twelve cases, the null hypothesis of $a=0$ is not rejected, and only in three cases is the null hypothesis of $b=1$ rejected. In fact, two implied correlation forecasts and three GARCH-based forecasts pass the joint test of partial optimality. Yet, this good performance does not necessarily imply better goodness-of-fit measures; i.e., these forecasts provide the highest adjusted $R^{2} s$ in just three of the five cases. Note that $R^{2} s$ for the correlation forecasts are substantially higher than reported results for the implied volatilities of FX rates. ${ }^{11}$ This result is consistent with the view that, at least for some financial variables, correlations tend to be more stable and more predictability than volatilities.

However, for the franc trio, none of the forecasts are consistently partially optimal. Of the twelve cases examined, only three-month $\hat{\rho}_{\mathrm{G}}\left(\varepsilon_{\mathrm{DEM} / \mathrm{USD}}, \varepsilon_{\mathrm{CHF} / \mathrm{USD}}\right)_{\mathrm{t}, \mathrm{T}}$ does not reject the joint null hypothesis of partial optimality. The regression results also confirm that the forecasts' performance is not uniform over the three correlations in the trio. Specifically, implied correlation performs much better with respect to $\rho\left(\varepsilon_{\mathrm{DEM} / \mathrm{USD}}, \varepsilon_{\mathrm{CHF} / \mathrm{USD}}\right)_{\mathrm{t}, \mathrm{T}}$ with $\mathrm{R}^{21}$ s of 0.37 and 0.27 for the one- and three-month horizons, respectively. The $\mathrm{R}^{2}$, $\mathrm{s}$ for the other two correlations are below 0.10 . These results indicate that the implied correlations for this currency trio do not efficiently incorporate the information upon which they are based. There are a number of possible reasons for this result, such as low trading volume, improper use of the option pricing model or misspecification of the option pricing model.

\section{Encompassing Regressions}

Table 5 reports the results for the encompassing regressions in which the realized correlations are regressed on a constant and a set of forecasts. For each case of the twelve cases, the set includes implied correlations, the GARCH-based correlation forecasts, and the historical and EWMA correlation forecasts with the highest $\mathrm{R}^{2}$ in the partial optimality regressions. In

11 While a variety of such regression results are reported in the literature, the $\mathrm{R}^{2} \mathrm{~s}$ for the regression of realized volatility on a constant and implied volatility are generally lower. Jorion (1995) reports $\mathrm{R}^{2} \mathrm{~s}$ in the range of 0.02 to 0.05 . Galati and Tsatsaronis (1995) report an $\mathrm{R}^{2}$ of 0.30 in the case of the USD/ British pound, and Guo (1996) reports a $\mathrm{R}^{2}$ of 0.10 for the USD/JPY volatility. 
general, the encompassing regressions for both trios provide mixed results with regard to the usefulness of implied correlations for forecasting realized correlations. Once again, implied correlations are found to be useful in some, but not all, cases.

Specifically, for the yen trio, the three main results can be summarized as follows. First, implied correlations do seem to contain information not present in the time-series forecasts in certain cases. The coefficients on implied correlation are significantly positive in three of the six cases. The second result is that implied correlations do not fully incorporate all the information extractable from time-series data. The Wald test results, listed at the bottom of the table, never reject the null hypothesis that the regression coefficients on all the time-series forecasts are zero, suggesting that they are not encompassed by implied correlations and do provide additional information useful in predicting realized correlation.

These findings are inconsistent with those of Campa and Chang (1997), who find that time-series forecasts of $\rho\left(\varepsilon_{\mathrm{DEM} / \mathrm{USD}}, \varepsilon_{\mathrm{YEN} / \mathrm{USD}}\right)_{\mathrm{t}, \mathrm{T}}$ do not contribute incremental information to implied correlation forecasts. We currently attribute this difference in conclusions to the time periods of the two studies. Campa and Chang's study is based on data from January 3, 1989 through May 23, 1995, which overlaps with roughly the beginning 70 percent of our data from October 2, 1990 through April 2, 1997. The different sample periods may give rise to different results if there is time-variation in the forecasting ability of implied correlations. In fact, Table 6 provides some evidence that this may be the case. The table reports the results of encompassing regressions for one-month $\rho\left(\varepsilon_{\mathrm{DEM} / \mathrm{USD}}, \varepsilon_{\mathrm{YEN} / \mathrm{USD}}\right)_{\mathrm{t}, \mathrm{T}}$ based on eight, non-overlapping subsamples of 200 observations each. The table shows that the coefficient on implied correlation was generally significant in the first half of the sample from October 1990 to October 1993. However, for the second half of our data sample (November 1993 to April 1997), the coefficient is generally insignificant, suggesting that the inclusion of implied correlations does not improve the performance of the time-series forecasts. The fact that implied correlation performed differently in these non-overlapping periods may explain the differences between Campa and Chang's and our results, but further analysis is necessary.

The third result from the encompassing regressions for the yen trio is that the GARCHbased correlation forecasts seem to best incorporate the information in the historical, time-series 
data. In three of six cases, the regression coefficient on the GARCH-based correlation forecast is significant. The other forecasts based on historical data do not consistently provide incremental information useful in forecasting, although the Wald test never rejects the null hypothesis that the coefficients on all the time-series forecasts are zero.

With respect to the franc trio, Table 5, Panels C and D report the results of the encompassing regressions. Once again, there is no forecast that consistently provides useful information not contained in the other forecasts. Implied correlation incrementally improves the performance of the other forecasts for $\rho\left(\varepsilon_{\mathrm{DEM} / \mathrm{USD}}, \varepsilon_{\mathrm{CHF} / \mathrm{USD}}\right)_{\mathrm{t}, \mathrm{T}}$, which has the least variability of all the realized correlations examined. For the two other correlations, the coefficients on implied correlation are never significantly positive. (In fact, far from demonstrating implied correlation's predictive ability, they are even negative in two cases.) While the GARCH-based forecasts do not add information for $\rho\left(\varepsilon_{\mathrm{DEM} / \mathrm{USD}}, \varepsilon_{\mathrm{CHF} / \mathrm{USD}}\right)_{\mathrm{t}, \mathrm{T}}$, they tend to provide incremental information for the two other correlations. As for the simple forecasts, whereas the coefficients on the historical correlations are never significant, some of the EWMA forecasts do provide additional information useful in forecasting the realized correlation. However, there is no EWMA-based forecasts that adds information across all the correlations in the trio. In short, the encompassing regressions for the franc trio are generally less clear than those for the yen trio.

\section{Conclusion}

Several papers, such as Jorion (1995), indicate that implied volatilities from foreign exchange options are useful in forecasting subsequently realized volatility. This paper addresses the question of whether implied correlations are useful in forecasting subsequently realized correlation. Using daily, OTC data on exchange rate options in two currency trios, we examine all six of the implied correlations extractable. We compare the forecasting performance of these implied correlations against a number of alternative, time-series forecasts, such as simple historical correlations and correlation forecasts generated by a rolling, bivariate $\operatorname{GARCH}(1,1)$ model. Our main finding is that the performance of the implied correlations varies significantly across the currency trios and even across time periods.

For the yen trio, we find that although implied and GARCH-based correlation forecasts 
are biased, they generate lower root-mean-squared forecast errors than simple, time-series forecasts. Moreover, these forecasts are generally shown to be partially optimal with respect to the information sets used to create them. Encompassing regressions reveal that although each individual forecast has some predictive power, only implied and GARCH-based correlations provide useful information not present in the other forecasts. Thus, even though implied correlations do not fully incorporate all the information in the price history, they do contain information not found in it. This result indicates that implied correlations are worth calculating, but we also find that their performance, as well as that of the other forecasts, varies over time.

The results for the franc trio reveal that the value of implied correlation as a predictor of future realized correlation is not uniform across currency trios. We find that both in terms of accuracy and information content, implied correlation is useful in forecasting $\rho\left(\varepsilon_{\mathrm{DEM} / \mathrm{USD}}, \varepsilon_{\mathrm{CHF} / \mathrm{USD}}\right)_{\mathrm{t}, \mathrm{T}}$ in this trio. However, the economic benefits of employing the optionbased forecast in this case is small due to the low variability of this correlation. For the two other correlations in the trio, implied correlation is far from being superior to the time-series forecasts, although these forecasts also do not consistently provide good forecasts for the correlations in this trio. Only GARCH-based correlation appears to have at least some forecasting ability, providing useful forecasts for two of the three correlations.

The absence of significant forecast performance from the implied correlations in the franc trio as well as its inconsistent performance for the yen trio seem to challenge the value of implied correlations as predictors of realized correlation. From our results, we conclude that its predictive ability can only be determined empirically. These results raise the important question of why such option-based forecasts, which ostensibly include the price history as well as the market's expectations over the option's maturity, do not consistently outperform the time-series forecasts. There are two possible reasons for this poor performance. First, it could be that the Garman-Kohlhagen (1983) option pricing model commonly used to extract FX implied volatilities is misspecified. Second, it could be that the market for some of the options used to extract the implied correlations is not efficient. Although this seems unlikely for the yen trio, it is possible that the trading volume for options in the franc trio is not large enough to assure accurate market prices. Further research is needed to answer these questions. 


\section{References}

Amin, K.I. and Ng, V.K., 1997. "Inferring Future Volatility from the Information in Implied Volatility in Eurodollar Options: A New Approach," Review of Financial Studies, 10, 333-367.

Beckers, S., 1981. "Standard Deviations Implied in Option Prices as Predictors of Future Stock Price Variability," Journal of Banking and Finance, 5, 363-381.

Bodurtha, J.N. and Shen, Q., 1995. "Historical and Implied Measures of 'Value at Risk': The DM and Yen Case," Manuscript, Georgetown University.

Bollerslev, Tim. 1986. "Generalized Autoregressive Conditional Heteroskedasticity". Journal of Econometrics. 31, 307-327.

Bollerslev, T. and Engle, R.F., 1993. "Common Persistence in Conditional Variances," Econometrica, 61, 167-186.

Bollerslev, T., Engle, R.F. and Wooldridge, J.M., 1988. "A Capital Asset Pricing Model with Time-Varying Covariances," Journal of Political Economy, 96, 116-131.

Bollerslev, T., Engle, R.F. and Nelson, D.B., 1994. "ARCH Models," in Engle, R.F. and McFadden, D., eds. The Handbook of Econometrics, Volume 4, 2959-3038. Amsterdam: North-Holland.

Brown, B.W. and Maital, S., 1981. "What Do Economists Know? An Empirical Study of Experts' Expectations," Econometrica, 49, 491-504.

Campa, J.M. and Chang, P.H.K., 1997. “The Forecasting Ability of Correlations Implied in Foreign Exchange Options,” NBER Working Paper \#5974.

Chong, Y.Y. and Hendry, D.H., 1990. "Econometric Evaluation of Linear Macro-Econometric Models," Review of Economic Studies, 53, 671-690.

Cooper, S. and Weston, S., 1996. "Bank Checks," Risk, 9 (2), 23-27.

Diebold, F.X. and Mariano, R.S., 1995. "Comparing Predictive Accuracy,” Journal of Business and Economic Statistics, 13, 253-263.

Diebold, F.X. and Lopez, J.A., 1996. "Forecast Evaluation and Combination," The Handbook of Statistics, Volume 14: Statistical Methods in Finance, G.S. Maddala and C.R. Rao (eds.). Amsterdam: North-Holland, 241-268. 
Engle, R.F., 1982. "Autoregressive Conditional Heteroskedasticity with Estimates of the Variance of U.K. Inflation," Econometrica, 50, 987-1008.

Galati, G. and Tsatsaronis, C., 1995. “The Information Content of Implied Volatility from Currency Options," Manuscript, Bank for International Settlements.

Garman, M. B. and Kohlhagen, S.W., 1983. "Foreign Currency Option Values,” Journal of International Money and Finance, 2, 231-237.

Gibson, M.S. and Boyer, B.H., 1997. "Evaluating Forecasts of Correlation Using Option Pricing," International Finance Discussion Papers \#600, Board of Governors of the Federal Reserve System.

Guo, D., 1996. “The Predictive Power of Implied Stochastic Variance from Currency Options,” Journal of Futures Markets, 16, 915-942.

Hendricks, D., 1996. “Evaluation of Value-at-Risk Models Using Historical Data," Federal Reserve Bank of New York Economic Policy Review, 2, 39-69.

Hsieh, D.A., 1988. "The Statistical Properties of Daily Foreign Exchange Rates: 1974-1983," Journal of International Economics, 24, 129-145.

Hull, J.C. and White, A., 1987. "The Pricing of Options with Stochastic Volatility," Journal of Finance, 42, 281-300.

Jorion, P., 1995. "Predicting Volatility in the Foreign Exchange Market," Journal of Finance, 50, 507-528.

J.P. Morgan, 1996. RiskMetrics ${ }^{\mathrm{TM}}$ - Technical Document. Fourth edition, New York: J.P. Morgan.

Kroner, K.F., Kneafsey, K.P. and Claessens, S., 1995. "Forecasting Volatility in Commodity Markets," Journal of Forecasting, 14, 77-95.

Karolyi, G.A. and Stulz, R., 1996. "Why Do Markets Move Together? An Investigation of U.S.Japan Stock Return Comovements," Journal of Finance, 51, 951-986.

Longin, F. and Solnik, B., 1995. "Is the Correlation in International Equity Returns Constant: 1960-1990?," Journal of International Money and Finance, 14, 3-26.

Mahoney, J.M., 1995. “Correlation Products and Risk Management Issues," Federal Reserve Bank of New York Economic Policy Review, 1, 7-20. 
Mayhew, S., 1995. "Implied Volatility,” Financial Analysts Journal, July-August, 8-20.

Mincer, J. and Zarnowitz, V., 1969. "The Evaluation of Economic Forecasts," in Mincer, J. (ed.). Economic Forecasts and Expectations. National Bureau of Economic Research: New York.

Newey, W.K. and West, K.D., 1987. “A Simple Positive Semi-Definitive Heteroskedasticity and Autocorrelation Consistent Covariance Matrix,” Econometrica, 55, 703-708.

Siegel, A.F., 1997. "International Currency Relationship Information Revealed by Cross-Option Prices," Journal of Futures Markets, 17, 369-384.

Singer, B.D., Terhaar, K. and Zerolis, J., 1998. "Maintaining Consistent Global Asset Views (with a Little Help from Euclid)," Financial Analysts Journal, January/February, 63-71. 


\section{Table 1, Panel A. \\ Descriptive Statistics for the Implied Correlations in the USD/DEM/JPY Currency-Trio}

This panel presents the means, standard deviations, coefficients of skewness and kurtosis, and maximum and minimum values for implied correlations, as calculated from the implied volatilities of at-the-money, FX options with the forward rate set as the strike price. The notation $\hat{\rho}_{\mathrm{IV}}\left(\varepsilon_{\mathrm{A} / \mathrm{C}}, \varepsilon_{\mathrm{B} / \mathrm{C}}\right)_{\mathrm{tT}}$ refers to the implied correlation at time $\mathrm{t}$ derived from the implied volatilities on options with maturities of $\mathrm{T}$ months for the changes in the logged, exchange rates between currencies A and B with respect to currency C. The observation period is October 2, 1990 through April 2,1997, which generates 1679 observations.

\begin{tabular}{|c|c|c|c|c|c|c|}
\hline & $\underline{\text { Mean }}$ & Std.Dev. & $\underline{\text { Skewness }}$ & $\underline{\text { Kurtosis }}$ & Maximum & $\underline{\text { Minimum }}$ \\
\hline$\hat{\rho}_{\mathrm{IV}}\left(\varepsilon_{\mathrm{DEM} / \mathrm{USD}}, \varepsilon_{\mathrm{JPY} / \mathrm{USD}}\right)_{\mathrm{t}, 1}$ & 0.5691 & 0.1094 & -0.3726 & 3.0431 & 0.8198 & 0.0471 \\
\hline$\hat{\rho}_{\mathrm{IV}}\left(\varepsilon_{\mathrm{DEM} / \mathrm{USD}}, \varepsilon_{\mathrm{JPY} / \mathrm{USD}}\right)_{\mathrm{t}, 3}$ & 0.5687 & 0.0858 & -0.1289 & 2.4269 & 0.7737 & 0.3021 \\
\hline$\hat{\rho}_{\mathrm{IV}}\left(\varepsilon_{\mathrm{USD} / \mathrm{DEM}}, \varepsilon_{\mathrm{JPY} / \mathrm{DEM}}\right)_{\mathrm{t}, 1}$ & 0.5243 & 0.1688 & 0.0036 & 2.4829 & 0.8952 & -0.0480 \\
\hline$\hat{\rho}_{\mathrm{IV}}\left(\varepsilon_{\mathrm{USD} / \mathrm{DEM}}, \varepsilon_{\mathrm{JPY} / \mathrm{DEM}}\right)_{\mathrm{t}, 3}$ & 0.5161 & 0.1513 & -0.0521 & 2.3061 & 0.8209 & 0.0303 \\
\hline$\hat{\rho}_{\mathrm{IV}}\left(\varepsilon_{\mathrm{USD} / \mathrm{JPY}}, \varepsilon_{\mathrm{DEM} / \mathrm{JPY}}\right)_{\mathrm{t}, 1}$ & 0.3755 & 0.1970 & -0.6063 & 2.8926 & 0.7817 & -0.4140 \\
\hline$\hat{\rho}_{\mathrm{IV}}\left(\varepsilon_{\mathrm{USD} / \mathrm{JPY}}, \varepsilon_{\mathrm{DEM} / \mathrm{JPY}}\right)_{\mathrm{t}, 3}$ & 0.3930 & 0.1570 & -0.6988 & 2.7740 & 0.6911 & -0.1470 \\
\hline
\end{tabular}




\section{Table 1, Panel B. \\ Descriptive Statistics for the Implied Correlations in the USD/DEM/CHF Currency-Trio}

This panel presents the means, standard deviations, coefficients of skewness and kurtosis, and maximum and minimum values for implied correlations, as calculated from the implied volatilities of at-the-money, FX options with the forward rate set as the strike price. The notation $\hat{\rho}_{\mathrm{IV}}\left(\varepsilon_{\mathrm{A} / \mathrm{C}}, \varepsilon_{\mathrm{B} / \mathrm{C}}\right)_{\mathrm{tT}}$ refers to the implied correlation at time $\mathrm{t}$ derived from the implied volatilities on options with maturities of $\mathrm{T}$ months on the changes in logged, exchange rates between currencies A and B with respect to currency C. The observation period is September 13, 1993 through April 2, 1997 (910 observations).

\begin{tabular}{|lcccccc|}
\hline & $\underline{\text { Mean }}$ & $\underline{\text { Std.Dev. }}$ & $\underline{\text { Skewness }}$ & $\underline{\text { Kurtosis }}$ & $\underline{\text { Maximum }}$ & $\underline{\text { Minimum }}$ \\
$\hat{\rho}_{\mathrm{IV}}\left(\varepsilon_{\mathrm{DEM} / \mathrm{USD}}, \varepsilon_{\mathrm{CHF} / \mathrm{NSD}}\right)_{\mathrm{t}, 1}$ & 0.9134 & 0.0347 & -0.1551 & 2.1113 & 0.9815 & 0.8310 \\
$\hat{\rho}_{\mathrm{IV}}\left(\varepsilon_{\mathrm{DEM} / \mathrm{USD}}, \varepsilon_{\mathrm{CHF} / \mathrm{USD}}\right)_{\mathrm{t}, 3}$ & 0.9169 & 0.0261 & -0.0459 & 2.2126 & 0.9749 & 0.8506 \\
$\hat{\rho}_{\mathrm{IV}}\left(\varepsilon_{\mathrm{USD} / \mathrm{DEM}}, \varepsilon_{\mathrm{CHF} / \mathrm{DEM}}\right)_{\mathrm{t}, 1}$ & -0.0216 & 0.1372 & -0.3313 & 3.2780 & 0.4952 & -0.4993 \\
$\hat{\rho}_{\mathrm{IV}}\left(\varepsilon_{\mathrm{USD} / \mathrm{DEM}}, \varepsilon_{\mathrm{CHF} / \mathrm{DEM}}\right)_{\mathrm{t}, 3}$ & -0.0070 & 0.1175 & -0.1516 & 2.6989 & 0.4166 & -0.3968 \\
$\hat{\rho}_{\mathrm{IV}}\left(\varepsilon_{\mathrm{USD} / \mathrm{CHF}}, \varepsilon_{\mathrm{DEM} / \mathrm{CHF}}\right)_{\mathrm{t}, 1}$ & 0.4156 & 0.1133 & 0.0286 & 2.4365 & 0.6721 & -0.1079 \\
$\hat{\rho}_{\mathrm{IV}}\left(\varepsilon_{\mathrm{USD} / \mathrm{CHF}}, \varepsilon_{\mathrm{DEM} / \mathrm{CHF}}\right)_{\mathrm{t}, 3}$ & 0.3979 & 0.1079 & 0.3202 & 2.1620 & 0.6301 & -0.0033 \\
\hline
\end{tabular}


Figure 1, Panel A.

One-Month and Three-Month Implied Correlations in the USD/DEM/JPY Currency Trio
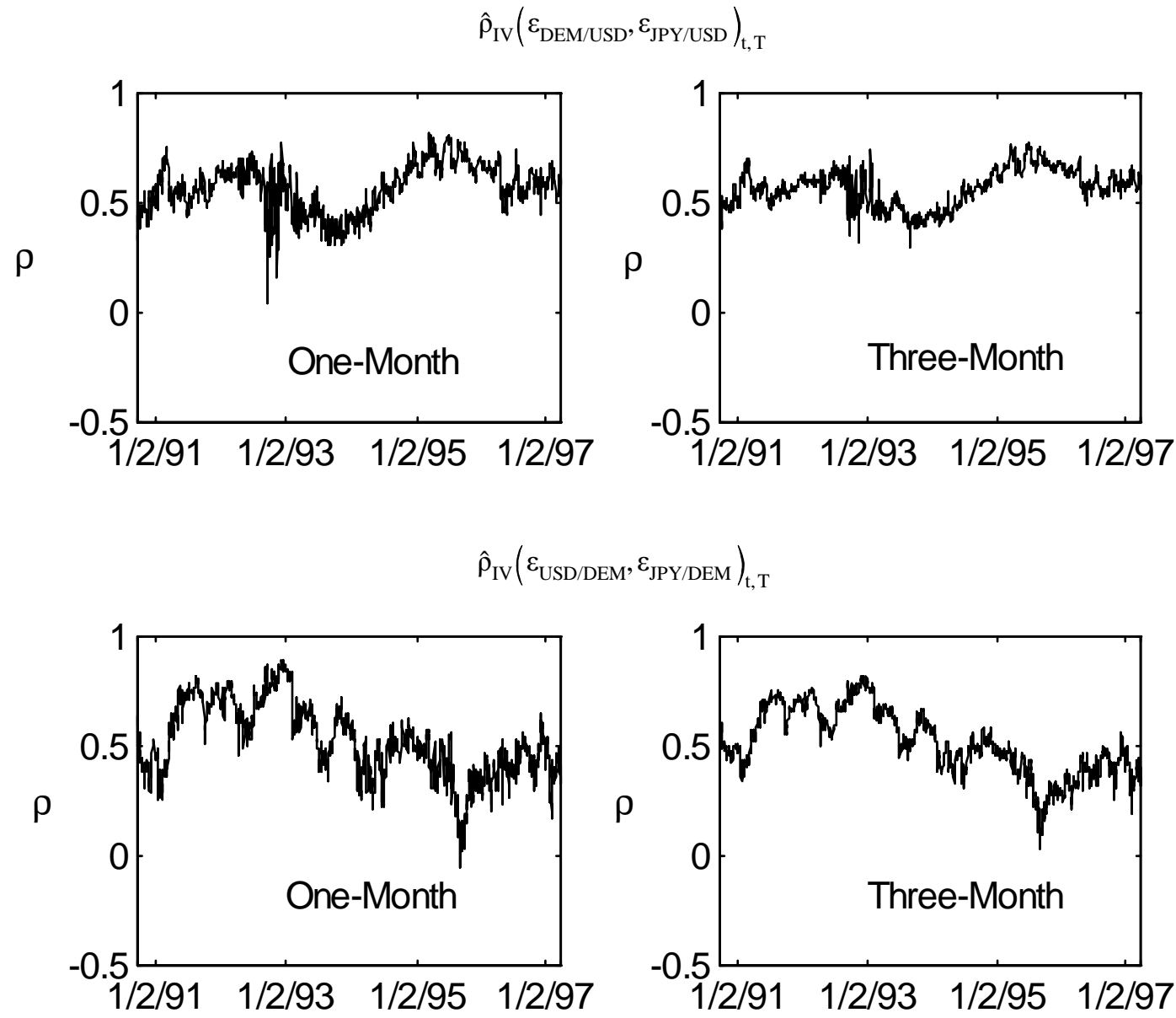

$$
\hat{\rho}_{\mathrm{IV}}\left(\varepsilon_{\mathrm{USD} / \mathrm{JPY}}, \varepsilon_{\mathrm{DEM} / \mathrm{JPY} Y}\right)_{\mathrm{t}, \mathrm{T}}
$$
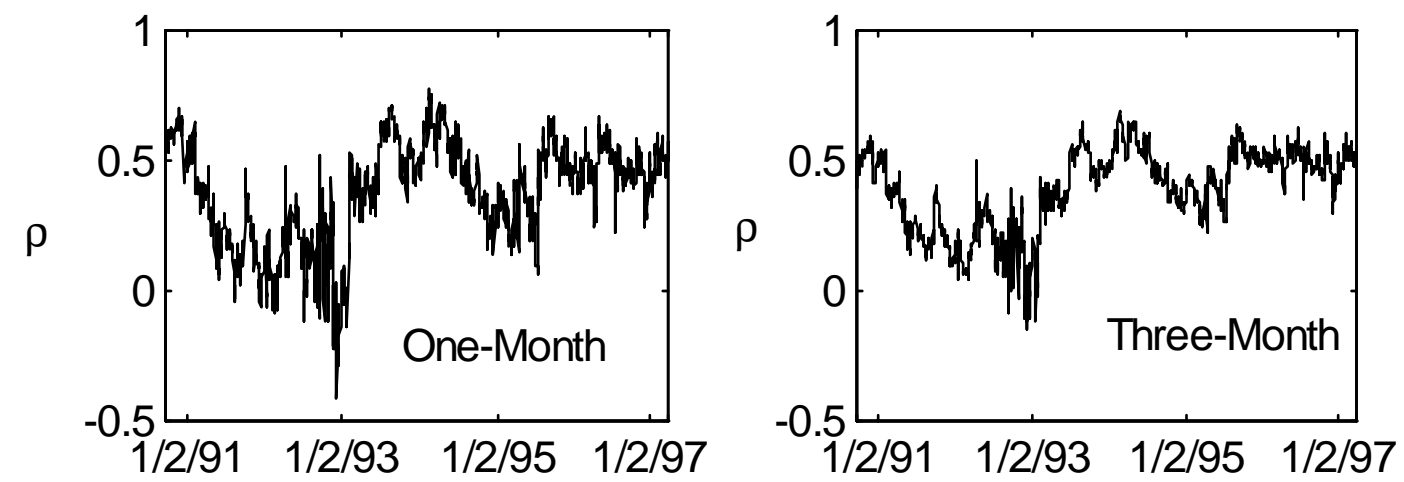
Figure 1, Panel B.

One-Month and Three-Month Implied Correlations in the USD/DEM/CHF Currency Trio
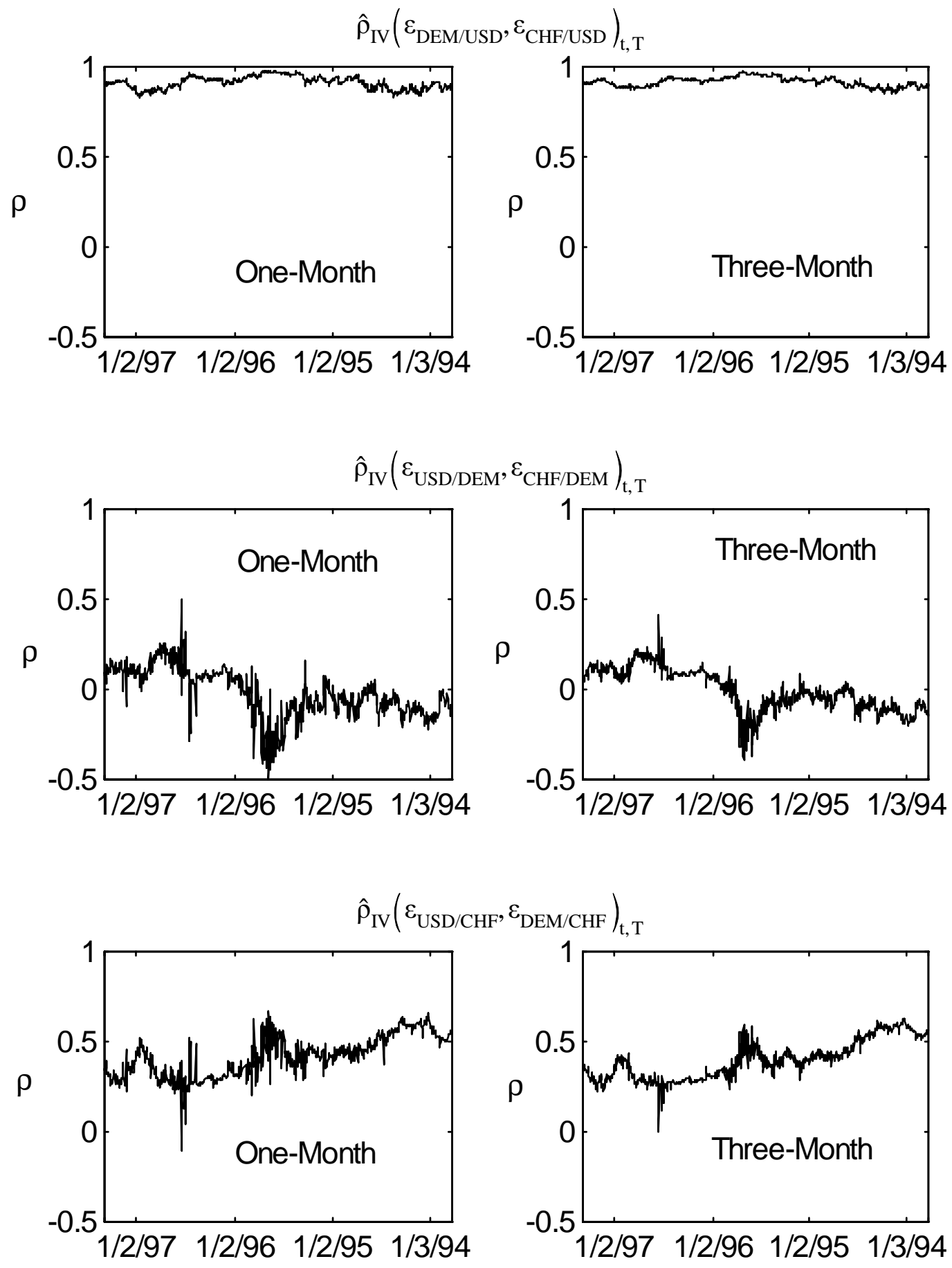


\section{Table 2, Panel A.}

\section{Bivariate GARCH(1,1) Parameter Estimates for the Exchange Rate Pairs in the USD/DEM/JPY Currency Trio}

This panel reports the estimation results for the bivariate $\operatorname{GARCH}(1,1)$ model with a constant conditional mean for the three exchange rate pairs in the USD/DEM/JPY currency-trio. The data observation period is from January 3, 1980 through October 2, 1990 (2714 observations). Following Bollerslev, Engle and Wooldridge (1988), the model is specified for the log exchange rates between currencies $\mathrm{A}$ and $\mathrm{B}$ with respect to currency $\mathrm{C}$, denoted $\mathrm{y}_{\mathrm{t}+1}=\left[\mathrm{y}_{\mathrm{A} / \mathrm{C}, \mathrm{t}+1} ; \mathrm{y}_{\mathrm{B} / \mathrm{C}, \mathrm{t}+1}\right]^{\prime}$, as

$$
\begin{gathered}
100 \Delta \mathrm{y}_{\mathrm{t}+1}=\mu+\varepsilon_{\mathrm{t}+1} \\
\varepsilon_{\mathrm{t}+1} \mid \Omega_{\mathrm{t}} \sim \mathrm{N}\left(0, \mathrm{H}_{\mathrm{t}+1}\right) \\
\mathrm{h}_{\mathrm{ij}, \mathrm{t}+1}=\omega_{\mathrm{ij}}+\alpha_{\mathrm{ij}} \varepsilon_{\mathrm{i}, \mathrm{t}} \varepsilon_{\mathrm{j}, \mathrm{t}}+\beta_{\mathrm{ij}} \mathrm{h}_{\mathrm{ij}, \mathrm{t}},
\end{gathered}
$$

where $\mu$ is a $(2 \times 1)$ constant conditional mean vector, $H_{t+1}$ is a (2x2) variance-covariance matrix and $h_{i j, t+1}$ is its $i, j^{\text {th }}$ element where $\mathrm{i}, \mathrm{j}=1,2 . \mathrm{LR}_{\mathrm{MA}}$ is the likelihood ratio statistic testing the null-hypothesis of that the diagonal MA(1)

\begin{tabular}{|c|c|c|c|c|c|c|}
\hline & \multicolumn{2}{|c|}{$\underline{\mathrm{DEM}}_{\mathrm{USD}} \& \mathrm{JPY}_{\mathrm{USD}}$} & \multicolumn{2}{|c|}{ 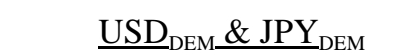 } & \multicolumn{2}{|c|}{$\underline{\mathrm{USD}}_{\mathrm{JPY}} \stackrel{\& \mathrm{DEM}_{\mathrm{JPY}}}{ }$} \\
\hline & Parameter & Standard & Parameter & Standard & Parameter & Standard \\
\hline & $\underline{\text { Estimate }}$ & $\underline{\text { Error }}$ & $\underline{\text { Estimate }}$ & $\underline{\text { Error }}$ & $\underline{\text { Estimate }}$ & $\underline{\text { Error }}$ \\
\hline$\mu_{1}$ & -0.0065 & 0.0121 & 0.0083 & 0.0125 & -0.0155 & 0.0115 \\
\hline$\mu_{2}$ & 0.0118 & 0.0113 & $0.0208^{*}$ & 0.0082 & $-0.0186^{*}$ & 0.0075 \\
\hline$\omega_{11}$ & $0.0185^{*}$ & 0.0027 & $0.0217^{*}$ & 0.0041 & $0.0276^{*}$ & 0.0033 \\
\hline$\omega_{12}$ & $0.0149 *$ & 0.0019 & $0.0043^{*}$ & 0.0013 & $0.0048^{*}$ & 0.0007 \\
\hline$\omega_{22}$ & $0.0244 *$ & 0.0027 & $0.0095 *$ & 0.0019 & $0.0074 *$ & 0.0013 \\
\hline$\alpha_{11}$ & $0.1353 *$ & 0.0100 & $0.1184^{*}$ & 0.0107 & $0.1276^{*}$ & 0.0092 \\
\hline$\alpha_{12}$ & $0.1180^{*}$ & 0.0087 & $0.1202 *$ & 0.0100 & $0.1320^{*}$ & 0.0085 \\
\hline$\alpha_{22}$ & $0.1196^{*}$ & 0.0098 & $0.1628 *$ & 0.0157 & $0.1512^{*}$ & 0.0117 \\
\hline$\beta_{11}$ & $0.8441 *$ & 0.0105 & $0.8470^{*}$ & 0.0125 & $0.8285^{*}$ & 0.0122 \\
\hline$\beta_{12}$ & $0.8551 *$ & 0.0094 & $0.8512 *$ & 0.0106 & $0.8421 *$ & 0.0099 \\
\hline$\beta_{22}$ & $0.8397 *$ & 0.0113 & $0.8159 *$ & 0.0157 & $0.8376^{*}$ & 0.0122 \\
\hline \multicolumn{2}{|c|}{ Log Likelihood } & -436.1 & \multicolumn{2}{|c|}{-436.5} & \multicolumn{2}{|c|}{-437.4} \\
\hline $\mathrm{LR}_{\mathrm{N}}$ & \multicolumn{2}{|c|}{0.018} & \multicolumn{2}{|c|}{0.326} & \multicolumn{2}{|c|}{0.576} \\
\hline
\end{tabular}
matrix $\theta$ in the alternative conditional mean specification $\Delta y_{t+1}=\mu+\theta \varepsilon_{t}+\varepsilon_{t+1}$ has parameters equal to zero. The statistic is distributed $\chi^{2}(2)$.

* Indicates statistical significance at the 5 percent level. 


\section{Table 2, Panel B.}

\section{Bivariate GARCH(1,1) Parameter Estimates for the Exchange Rate Pairs in the USD/DEM/CHF Currency Trio}

This panel reports the estimation results for the bivariate $\operatorname{GARCH}(1,1)$ model with a constant conditional mean for the three exchange rate pairs in the USD/DEM/JPY currency-trio. The data observation period is from January 3, 1980 through October 2, 1990 (2714 observations). Following Bollerslev, Engle and Wooldridge (1988), the model is specified for the log exchange rates between currencies $\mathrm{A}$ and $\mathrm{B}$ with respect to currency $\mathrm{C}$, denoted $\mathrm{y}_{\mathrm{t}+1}=\left[\mathrm{y}_{\mathrm{A} / \mathrm{C}, \mathrm{t}+1} ; \mathrm{y}_{\mathrm{B} / \mathrm{C}, \mathrm{t}+1}\right]^{\prime}$, as

$$
\begin{gathered}
100 \Delta \mathrm{y}_{\mathrm{t}+1}=\mu+\varepsilon_{\mathrm{t}+1} \\
\varepsilon_{\mathrm{t}+1} \mid \Omega_{\mathrm{t}} \sim \mathrm{N}\left(0, \mathrm{H}_{\mathrm{t}+1}\right) \\
\mathrm{h}_{\mathrm{ij}, \mathrm{t}+1}=\omega_{\mathrm{ij}}+\alpha_{\mathrm{ij}} \varepsilon_{\mathrm{i}, \mathrm{t}} \varepsilon_{\mathrm{j}, \mathrm{t}}+\beta_{\mathrm{ij}} \mathrm{h}_{\mathrm{ij}, \mathrm{t}},
\end{gathered}
$$

where $\mu$ is a $(2 \times 1)$ constant conditional mean vector, $H_{t+1}$ is a (2x2) variance-covariance matrix and $h_{i j, t+1}$ is its $i, j^{\text {th }}$ element where $\mathrm{i}, \mathrm{j}=1,2 . \mathrm{LR}_{\mathrm{MA}}$ is the likelihood ratio statistic testing the null-hypothesis of that the diagonal MA(1)

\begin{tabular}{|c|c|c|c|c|c|c|}
\hline & \multicolumn{2}{|c|}{$\underline{\mathrm{DEM}}_{\mathrm{USD}} \& \mathrm{CHF}_{\mathrm{USD}}$} & \multicolumn{2}{|c|}{$\underline{\mathrm{USD}}_{\mathrm{DEM}} \underline{\& \mathrm{CHF}}{ }_{\mathrm{DEM}}$} & \multicolumn{2}{|c|}{$\underline{\mathrm{USD}}_{\mathrm{CHF}} \underline{\& \mathrm{DEM}_{\mathrm{CHF}}}$} \\
\hline & Parameter & Standard & Parameter & Standard & Parameter & Standard \\
\hline & $\underline{\text { Estimate }}$ & $\underline{\text { Error }}$ & $\underline{\text { Estimate }}$ & $\underline{\text { Error }}$ & Estimate & $\underline{\text { Error }}$ \\
\hline$\mu_{1}$ & 0.0003 & 0.0113 & 0.0034 & 0.0115 & 0.0049 & 0.0127 \\
\hline$\mu_{2}$ & -0.0025 & 0.0123 & -0.0031 & 0.0045 & 0.0031 & 0.0046 \\
\hline$\omega_{11}$ & $0.0163^{*}$ & 0.0027 & $0.0139 *$ & 0.0031 & $0.0171 *$ & 0.0040 \\
\hline$\omega_{12}$ & $0.0153 *$ & 0.0025 & $0.0004 *$ & 0.0001 & $0.0030 *$ & 0.0007 \\
\hline$\omega_{22}$ & $0.0172 *$ & 0.0029 & $0.0023 *$ & 0.0006 & $0.0026^{*}$ & 0.0006 \\
\hline$\alpha_{11}$ & $0.0874^{*}$ & 0.0066 & $0.1032 *$ & 0.0102 & $0.0965^{*}$ & 0.0098 \\
\hline$\alpha_{12}$ & $0.0802 *$ & 0.0062 & $0.0584^{*}$ & 0.0092 & $0.0657^{*}$ & 0.0095 \\
\hline$\alpha_{22}$ & $0.0765 *$ & 0.0062 & $0.0845^{*}$ & 0.0139 & $0.0957 *$ & 0.0127 \\
\hline$\beta_{11}$ & $0.8883 *$ & 0.0084 & $0.8799 *$ & 0.0106 & $0.8841 *$ & 0.0114 \\
\hline$\beta_{12}$ & $0.8967 *$ & 0.0079 & $0.9194 *$ & 0.0115 & $0.9050^{*}$ & 0.0138 \\
\hline$\beta_{22}$ & $0.9011 *$ & 0.0083 & $0.8923^{*}$ & 0.0188 & $0.8798 *$ & 0.0171 \\
\hline \multicolumn{2}{|c|}{ Log Likelihood } & & \multicolumn{2}{|c|}{-418.8} & \multicolumn{2}{|c|}{-418.2} \\
\hline $\mathrm{LR}_{\mathrm{N}}$ & \multicolumn{2}{|c|}{0.442} & \multicolumn{2}{|c|}{0.206} & \multicolumn{2}{|c|}{0.460} \\
\hline
\end{tabular}
matrix $\theta$ in the alternative conditional mean specification $\Delta y_{t+1}=\mu+\theta \varepsilon_{t}+\varepsilon_{t+1}$ has parameters equal to zero. The statistic is distributed $\chi^{2}(2)$.

* Indicates statistical significance at the 5 percent level. 


\section{Table 2, Panel C.}

\section{Parameter Estimates for the Bivariate GARCH(1,1) Model for the Exchange Rate Pair $\mathbf{y}_{\mathrm{DEM} / \mathrm{USD}}$ and $\mathbf{y}_{\mathrm{JPY} / \mathrm{USD}}$}

This panel reports, in the first two columns, the estimation results for the bivariate GARCH( 1,1$)$ model with a constant conditional mean for the exchange rate pair $\mathrm{y}_{\mathrm{t}+1}=\left[\mathrm{y}_{\mathrm{DEM} / \mathrm{USD}, \mathrm{t}+1} ; \mathrm{y}_{\mathrm{JPY} / \mathrm{USD}, \mathrm{t}+1}\right]$. The data observation period is the 1000 observations prior to October 2, 1990, the beginning of the relevant out-of-sample period. Following Bollerslev, Engle and Wooldridge (1988), the model is specified as

$$
\begin{gathered}
100 \Delta \mathrm{y}_{\mathrm{t}+1}=\mu+\varepsilon_{\mathrm{t}+1} \\
\varepsilon_{\mathrm{t}+1} \mid \Omega_{\mathrm{t}} \sim \mathrm{N}\left(0, \mathrm{H}_{\mathrm{t}+1}\right) \\
\mathrm{h}_{\mathrm{ij}, \mathrm{t}+1}=\omega_{\mathrm{ij}}+\alpha_{\mathrm{ij}} \varepsilon_{\mathrm{i}, \mathrm{t}} \varepsilon_{\mathrm{j}, \mathrm{t}}+\beta_{\mathrm{ij}} \mathrm{h}_{\mathrm{ij}, \mathrm{t}},
\end{gathered}
$$

where $\mathrm{H}_{t+1}$ is a $(2 \times 2)$ variance-covariance matrix and $h_{i j, t+1}$ is $i t s i, j^{\text {th }}$ element where $i, j=1,2$. The last three columns

\begin{tabular}{|c|c|c|c|c|c|}
\hline & \multicolumn{2}{|c|}{$\begin{array}{c}\text { Model } \\
\text { for October 2, } 1990\end{array}$} & \multicolumn{3}{|c|}{$\begin{array}{l}\text { Rolling Model } \\
\text { from October 2, } 1990 \text { through April 2, } 1997\end{array}$} \\
\hline & Parameter & Standard & Minimum & Maximum & Mean \\
\hline & Estimates & Errors & $\underline{\text { Value }}$ & $\underline{\text { Value }}$ & Value \\
\hline$\mu_{1}$ & 0.0134 & 0.0204 & -0.0140 & 0.0565 & 0.0206 \\
\hline$\mu_{2}$ & 0.0171 & 0.0202 & -0.0257 & 0.0462 & 0.0215 \\
\hline$\omega_{11}$ & $0.0145^{*}$ & 0.0034 & 0.0044 & 0.0198 & 0.0127 \\
\hline$\omega_{12}$ & $0.0140 *$ & 0.0025 & 0.0020 & 0.0149 & 0.0070 \\
\hline$\omega_{22}$ & $0.0242 *$ & 0.0034 & 0.0073 & 0.0260 & 0.0152 \\
\hline$\alpha_{11}$ & $0.1205^{*}$ & 0.0152 & 0.0424 & 0.1208 & 0.0739 \\
\hline$\alpha_{22}$ & $0.1204^{*}$ & 0.0124 & 0.0340 & 0.1219 & 0.0680 \\
\hline$\alpha_{33}$ & $0.1298 *$ & 0.0143 & 0.0549 & 0.1326 & 0.0839 \\
\hline$\beta_{11}$ & $0.8637^{*}$ & 0.0161 & 0.8606 & 0.9371 & 0.9082 \\
\hline$\beta_{22}$ & $0.8578 *$ & 0.0129 & 0.8531 & 0.9561 & 0.9156 \\
\hline$\beta_{33}$ & $0.8358 *$ & 0.0151 & 0.8292 & 0.9300 & 0.8872 \\
\hline
\end{tabular}
summarize the parameter values (minimum, maximum and mean) for the rolling GARCH estimations using 1,000 observations and running from October 2, 1990 through April 2, 1997.

* Indicates statistical significance at the 5 percent level. 
Figure 2.

One-Month Correlation for the Exchange Rate Pair $\mathbf{y}_{\text {DEM/USD }}$ and $\mathbf{y}_{\text {JPY/USD }}$ from October 2, 1990 through April 2, 1997:

Realized Correlation versus Various Forecasts

A. Realized and Implied Correlation

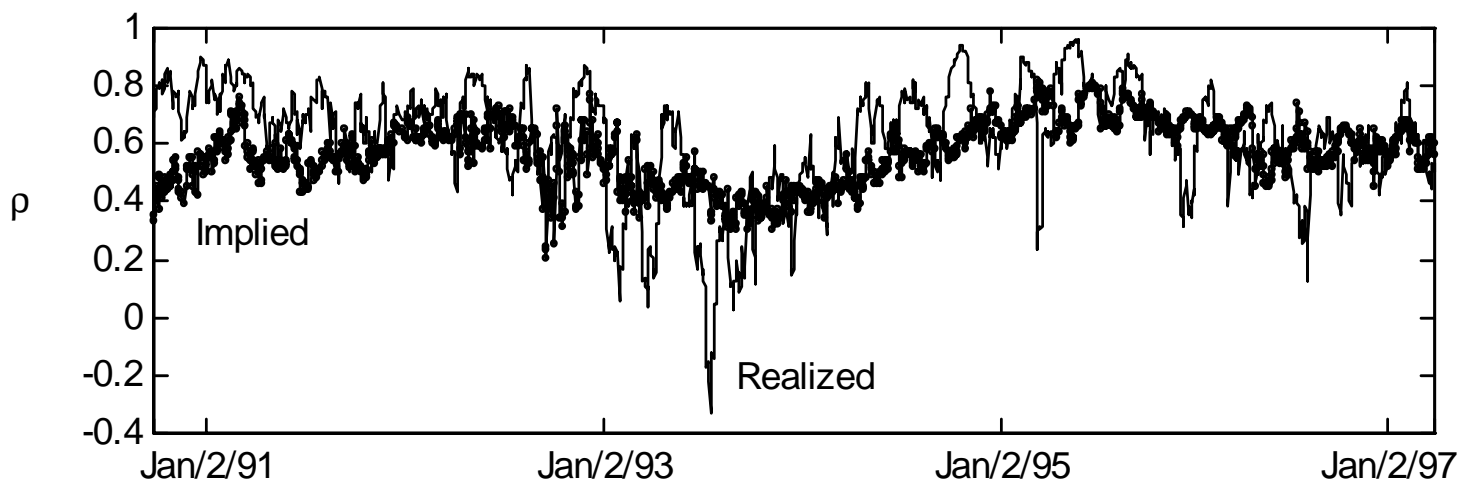

B. Realized and Biv. GARCH(1,1) based Correlation

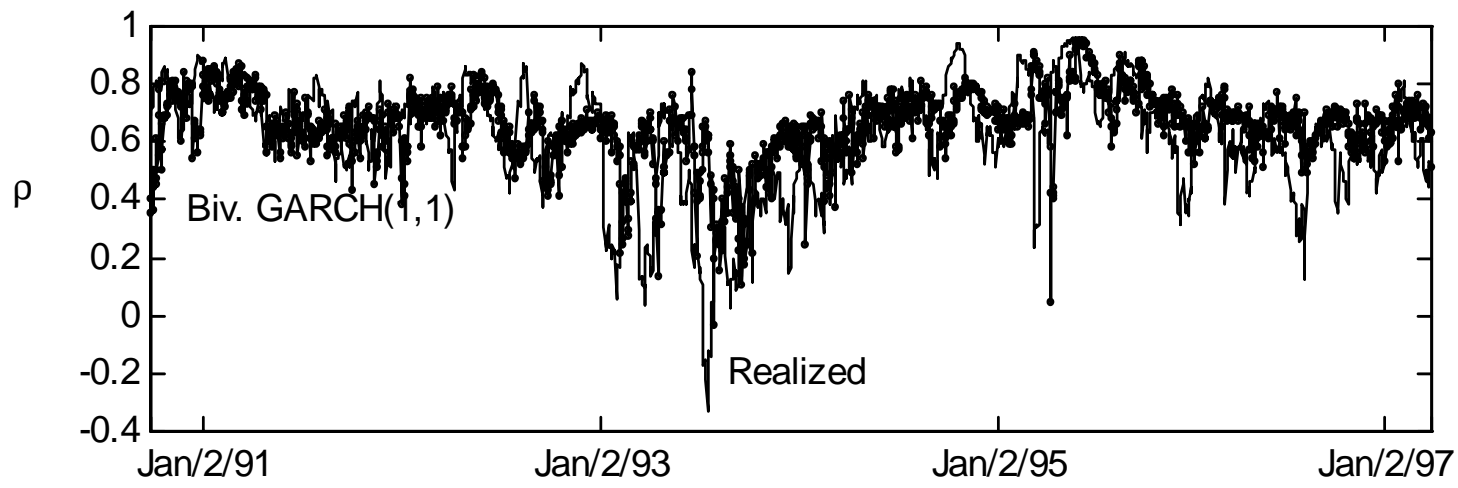

C. Realized and 20 days Historical Correlation

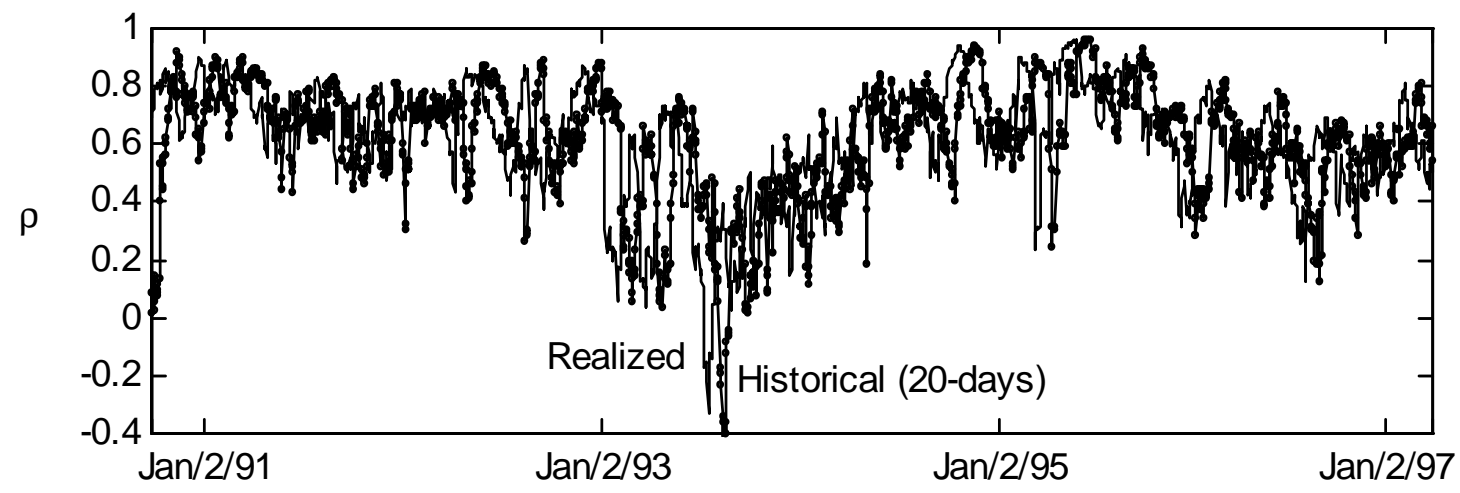


Figure 2. - Continued

One-Month Correlation for the Exchange Rate Pair $\mathbf{y}_{\mathrm{DEM} / \mathrm{USD}}$ and $\mathbf{y}_{\mathrm{JPY} / \mathrm{USD}}$ from October 2, 1990 through April 2, 1997:

Realized Correlation versus Various Forecasts

D. Realized and 120 days Historical Correlation

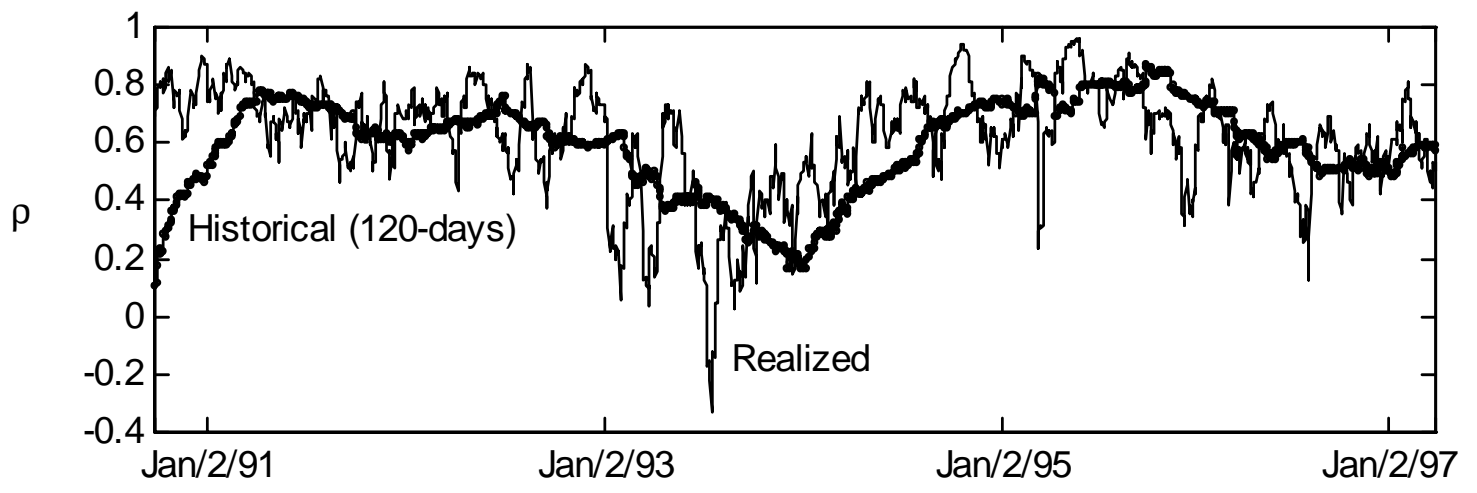

E. Realized and EWMA $(\lambda=0.94)$ Correlation

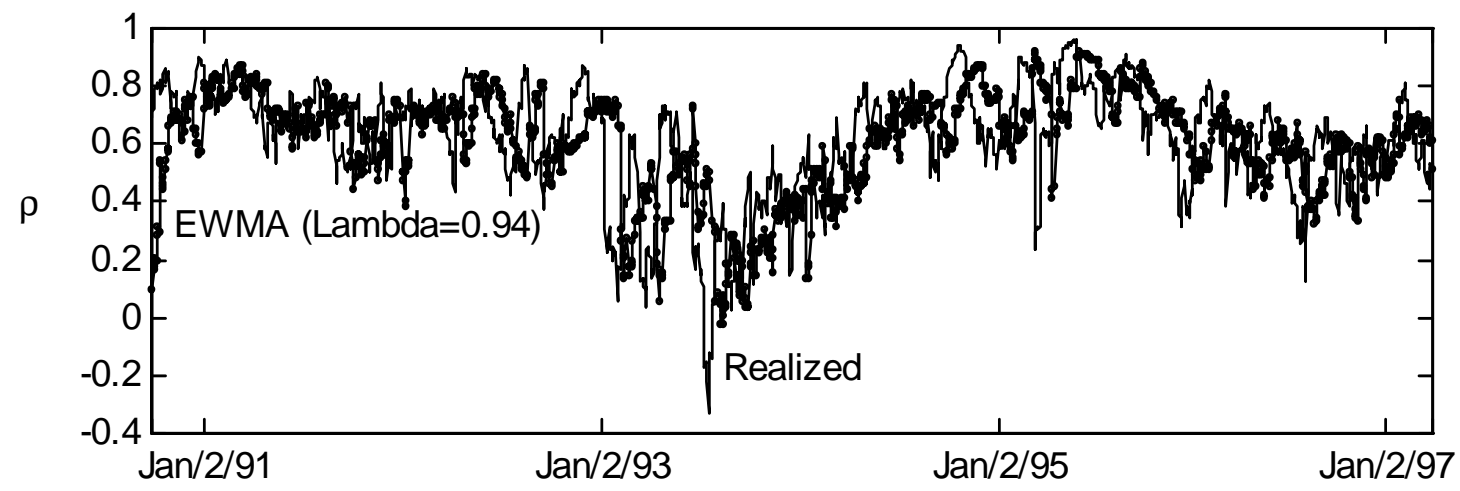

F. Realized and EWMA $(\lambda=0.99)$ Correlation

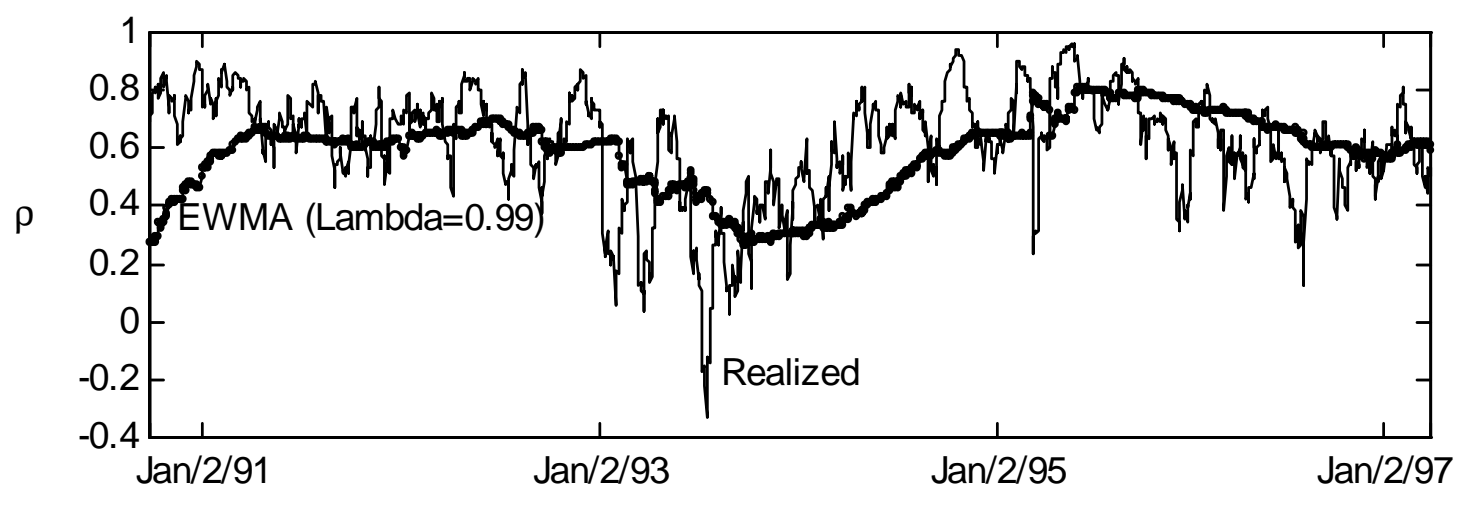


Table 3, Panel A.

\section{Analysis of Forecast Errors for the One-Month Correlation Forecasts in the USD/DEM/JPY Currency Trio}

This panel presents the analysis of the forecast errors between the forecasted and realized correlations for all three currency pairs in the USD/DEM/JPY trio. For the entire out-of-sample period from October 2, 1990 to April 2, 1997 (1679 observations), the columns under each correlation heading report the mean forecast errors (MFE), the root-mean-squared forecast errors (RMSFE), and the Diebold-Mariano test statistic (D\&M Test) for the null hypothesis of no difference in the forecast accuracy under the root-mean-squared loss function. MFE and RMSFE are defined as

$$
\operatorname{MFE}=\frac{1}{\mathrm{~N}} \sum_{\mathrm{t}=1}^{\mathrm{N}}\left(\rho(\bullet)_{\mathrm{t}, \mathrm{T}}-\hat{\rho}_{\mathrm{m}}(\bullet)_{\mathrm{t}, \mathrm{T}}\right), \text { and RMSFE }=\sqrt{\frac{1}{\mathrm{~N}} \sum_{\mathrm{t}=1}^{\mathrm{N}}\left(\rho(\bullet)_{\mathrm{t}, \mathrm{T}}-\hat{\rho}_{\mathrm{mt}}(\bullet)_{\mathrm{t}, \mathrm{T}}\right)^{2}}
$$

respectively, where $\rho(\bullet)_{\mathrm{t}, \mathrm{T}}$ denotes the realized correlation and $\hat{\rho}_{\mathrm{m}}(\bullet)_{\mathrm{t}, \mathrm{T}}$ denotes the correlation forecast according to model m. The statistical significance of the MFEs is assessed by running regressions of the forecast errors on a constant; the standard errors of the estimated parameters are corrected for the induced heteroskedasticity and autocorrelation using the Newey and West (1987) procedure. The minimum RMSFE value in each column is marked in bold.

\begin{tabular}{|c|c|c|c|c|c|c|c|c|c|}
\hline \multirow[b]{2}{*}{ Forecast Method } & \multicolumn{3}{|c|}{$\rho\left(\varepsilon_{\mathrm{DEM} / \mathrm{USD}}, \varepsilon_{\mathrm{JPY} / \mathrm{USD}}\right)_{\mathrm{t}, \mathrm{T}}$} & \multicolumn{3}{|c|}{$\rho\left(\varepsilon_{\mathrm{USD} / \mathrm{DEM}}, \varepsilon_{\mathrm{JPY} / \mathrm{DEM}}\right)_{\mathrm{t}, \mathrm{T}}$} & \multicolumn{3}{|c|}{$\rho\left(\varepsilon_{\mathrm{USD} / \mathrm{JPY}}, \varepsilon_{\mathrm{DEM} / \mathrm{JPY}}\right)_{\mathrm{t}, \mathrm{T}}$} \\
\hline & $\underline{\mathrm{MFE}}$ & $\underline{\text { RMSFE }}$ & D\&M Test & MFE & RMSFE & $\underline{\text { D\&M Test }}$ & MFE & $\underline{\mathrm{RMSFE}}$ & D\&M Test \\
\hline Implied & $0.048 * *$ & 0.182 & 1.10 & $-0.024 * *$ & 0.233 & - & $-0.080 * *$ & 0.297 & 1.17 \\
\hline H(20 days) & 0.003 & 0.218 & $4.30 * *$ & 0.002 & 0.281 & $4.24 * *$ & -0.001 & 0.323 & $2.67 * *$ \\
\hline H(60 days $)$ & 0.016 & 0.187 & 1.20 & -0.009 & 0.262 & $2.32 *$ & $-0.028 *$ & 0.295 & 0.89 \\
\hline H(120 days) & $0.026 * *$ & 0.189 & 1.08 & -0.013 & 0.279 & $3.13 * *$ & $-0.043 * *$ & 0.310 & 1.25 \\
\hline EWMA (0.94) & 0.009 & 0.188 & $2.54 * *$ & -0.005 & 0.243 & 0.97 & -0.016 & 0.288 & 0.63 \\
\hline EWMA (0.97) & 0.018 & 0.177 & 0.78 & -0.009 & 0.241 & 0.87 & $-0.034 *$ & 0.279 & 0.05 \\
\hline EWMA (0.99) & $0.031 * *$ & 0.190 & 1.27 & -0.010 & 0.257 & $2.03 *$ & $-0.069 * *$ & 0.319 & $1.58 *$ \\
\hline GARCH & $0.012 * *$ & 0.170 & - & $0.014 * *$ & 0.238 & 0.31 & $-0.017 * *$ & 0.278 & _ \\
\hline
\end{tabular}

** Indicates statistical significance at the 1 percent level.

* Indicates statistical significance at the 5 percent level. 
Table 3, Panel B.

\section{Analysis of Forecast Errors for the Three-Month Correlation Forecasts in the USD/DEM/JPY Currency Trio}

This panel presents the analysis of the forecast errors between the forecasted and realized correlations for all three currency pairs in the USD/DEM/JPY trio. For the entire out-of-sample period from October 2, 1990 to April 2, 1997 (1679 observations), the columns under each correlation heading report the mean forecast errors (MFE), the root-mean-squared forecast errors (RMSFE), and the Diebold-Mariano test statistic (D\&M Test) for the null hypothesis of no difference in the forecast accuracy under the root-mean-squared loss function. MFE and RMSFE are defined as

$$
\operatorname{MFE}=\frac{1}{\mathrm{~N}} \sum_{\mathrm{t}=1}^{\mathrm{N}}\left(\rho(\bullet)_{\mathrm{t}, \mathrm{T}}-\hat{\rho}_{\mathrm{m}}(\bullet)_{\mathrm{t}, \mathrm{T}}\right), \text { and RMSFE }=\sqrt{\frac{1}{\mathrm{~N}} \sum_{\mathrm{t}=1}^{\mathrm{N}}\left(\rho(\bullet)_{\mathrm{t}, \mathrm{T}}-\hat{\rho}_{\mathrm{mt}}(\bullet)_{\mathrm{t}, \mathrm{T}}\right)^{2}}
$$

respectively, where $\rho(\bullet)_{\mathrm{t}, \mathrm{T}}$ denotes the realized correlation and $\hat{\rho}_{\mathrm{m}}(\bullet)_{\mathrm{t}, \mathrm{T}}$ denotes the correlation forecast according to model m. The statistical significance of the MFEs is assessed by running regressions of the forecast errors on a constant; the standard errors of the estimated parameters are corrected for the induced heteroskedasticity and autocorrelation using the Newey and West (1987) procedure. The minimum RMSFE value in each column is marked in bold.

\begin{tabular}{|c|c|c|c|c|c|c|c|c|c|}
\hline \multirow[b]{2}{*}{ Forecast Method } & \multicolumn{3}{|c|}{$\rho\left(\varepsilon_{\mathrm{DEM} / \mathrm{USD}}, \varepsilon_{\mathrm{JPY} / \mathrm{USD}}\right)_{\mathrm{t}, \mathrm{T}}$} & \multicolumn{3}{|c|}{$\rho\left(\varepsilon_{\mathrm{USD} / \mathrm{DEM}}, \varepsilon_{\mathrm{JPY} / \mathrm{DEM}}\right)_{\mathrm{t}, \mathrm{T}}$} & \multicolumn{3}{|c|}{$\rho\left(\varepsilon_{\mathrm{USD} / \mathrm{JPY}}, \varepsilon_{\mathrm{DEM} / \mathrm{JPY}}\right)_{\mathrm{t}, \mathrm{T}}$} \\
\hline & MFE & RMSFE & D\&M Test & MFE & RMSFE & D\&M Test & MFE & RMSFE & D\&M Test \\
\hline Implied & $0.037 * *$ & 0.144 & 0.82 & -0.008 & 0.196 & - & $-0.072 * *$ & 0.269 & 0.84 \\
\hline $\mathrm{H}(20$ days $)$ & -0.008 & 0.189 & $3.90 * *$ & 0.009 & 0.282 & $4.36^{* *}$ & 0.025 & 0.332 & $1.89 *$ \\
\hline H(60 days $)$ & 0.005 & 0.150 & 0.90 & -0.001 & 0.253 & $3.13 * *$ & -0.002 & 0.279 & 0.80 \\
\hline H (120 days) & 0.015 & 0.157 & 1.02 & -0.006 & 0.257 & $3.24 * *$ & -0.017 & 0.300 & 1.28 \\
\hline EWMA (0.94) & -0.002 & 0.155 & $1.79 *$ & 0.003 & 0.243 & $2.97 * *$ & 0.010 & 0.290 & 1.02 \\
\hline EWMA (0.97) & 0.006 & 0.141 & 0.61 & -0.002 & 0.231 & $2.56^{* *}$ & -0.008 & 0.272 & 0.61 \\
\hline EWMA (0.99) & 0.020 & 0.161 & 1.40 & -0.003 & 0.229 & $2.29 *$ & $-0.043 *$ & 0.301 & 1.47 \\
\hline $\operatorname{GARCH}(1,1)$ & $-0.007 * *$ & 0.132 & - & $0.039 * *$ & 0.241 & $1.84 *$ & 0.010 & 0.252 & - \\
\hline
\end{tabular}

** Indicates statistical significance at the 1 percent level.

* Indicates statistical significance at the 5 percent level. 
Table 3, Panel C.

\section{Analysis of Forecast Errors for the One-Month Correlation Forecasts in the USD/DEM/CHF Currency Trio}

This panel presents the analysis of the forecast errors between the forecasted and realized correlations for all three currency pairs in the USD/DEM/CHF trio. For the entire out-of-sample period from September 13, 1993 to April 2, 1997 (910 observations), the columns under each correlation heading report the mean forecast errors (MFE), the root-mean-squared forecast errors (RMSFE), and the Diebold-Mariano test statistic (D\&M Test) for the null hypothesis of no difference in the forecast accuracy under the root-mean-squared loss function. MFE and RMSFE are defined as

$$
\text { MFE }=\frac{1}{\mathrm{~N}} \sum_{\mathrm{t}=1}^{\mathrm{N}}\left(\rho(\bullet)_{\mathrm{t}, \mathrm{T}}-\hat{\rho}_{\mathrm{m}}(\bullet)_{\mathrm{t}, \mathrm{T}}\right), \text { and RMSFE }=\sqrt{\frac{1}{\mathrm{~N}} \sum_{\mathrm{t}=1}^{\mathrm{N}}\left(\rho(\bullet)_{\mathrm{t}, \mathrm{T}}-\hat{\rho}_{\mathrm{mt}}(\bullet)_{\mathrm{t}, \mathrm{T}}\right)^{2}}
$$

respectively, where $\rho(\bullet)_{\mathrm{t}, \mathrm{T}}$ denotes the realized correlation and $\hat{\rho}_{\mathrm{m}}(\bullet)_{\mathrm{t}, \mathrm{T}}$ denotes the correlation forecast according to model $\mathrm{m}$. The statistical significance of the MFEs is assessed by running regressions of the forecast errors on a constant; the standard errors of the estimated parameters are corrected for the induced heteroskedasticity and autocorrelation using the Newey and West (1987) procedure. The minimum RMSFE value in each column is marked in bold.

\begin{tabular}{|c|c|c|c|c|c|c|c|c|c|}
\hline \multirow[b]{2}{*}{ Forecast Method } & \multicolumn{3}{|c|}{$\rho\left(\varepsilon_{\mathrm{DEM} / \mathrm{USD}}, \varepsilon_{\mathrm{CHF} / \mathrm{USD}}\right)_{\mathrm{t}, \mathrm{T}}$} & \multicolumn{3}{|c|}{$\rho\left(\varepsilon_{\text {USD/DEM }}, \varepsilon_{\text {CHF/DEM }}\right)_{t, \mathrm{~T}}$} & \multicolumn{3}{|c|}{$\rho\left(\varepsilon_{\mathrm{USD} / \mathrm{CHF}}, \varepsilon_{\mathrm{DEM} / \mathrm{CHF}}\right)_{\mathrm{t}, \mathrm{T}}$} \\
\hline & $\underline{\text { MFE }}$ & $\underline{\text { RMSFE }}$ & $\underline{D} \& \mathrm{M}$ Test & $\underline{\text { MFE }}$ & $\underline{\mathrm{RMSFE}}$ & D\&M Test & $\underline{\text { MFE }}$ & $\underline{\text { RMSFE }}$ & $\underline{D \& M}$ Test \\
\hline Implied & $0.017 * *$ & 0.041 & 1.55 & $-0.232 * *$ & 0.363 & $2.43 * *$ & $0.151^{* *}$ & 0.260 & $3.65 * *$ \\
\hline H(20 days) & -0.000 & 0.040 & $4.16^{* *}$ & -0.018 & 0.332 & $3.05^{* *}$ & 0.020 & 0.259 & $3.74 * *$ \\
\hline H(60 days) & -0.002 & 0.040 & $1.78^{*}$ & -0.006 & 0.292 & 0.78 & 0.003 & 0.230 & 1.54 \\
\hline H(120 days) & -0.004 & 0.046 & $1.65^{*}$ & -0.002 & 0.294 & $1.67^{*}$ & 0.001 & 0.227 & $1.74 *$ \\
\hline EWMA (0.94) & -0.001 & 0.035 & - & -0.010 & 0.293 & 1.03 & 0.008 & 0.226 & $2.87 * *$ \\
\hline EWMA (0.97) & -0.003 & 0.037 & 0.66 & -0.005 & 0.278 & 0.05 & 0.004 & 0.215 & $1.67^{*}$ \\
\hline EWMA (0.99) & -0.008 & 0.042 & 1.45 & -0.011 & 0.278 & - & 0.014 & 0.207 & 1.08 \\
\hline GARCH & -0.005 & 0.043 & 1.36 & -0.077 & 0.289 & 0.61 & $0.055^{* *}$ & 0.195 & - \\
\hline
\end{tabular}

** Indicates statistical significance at the 1 percent level.

* Indicates statistical significance at the 5 percent level. 
Table 3, Panel D.

Analysis of Forecast Errors for the Three-Month Correlation Forecasts in the USD/DEM/CHF Currency Trio

This panel presents the analysis of the forecast errors between the forecasted and realized correlations for all three currency pairs in the USD/DEM/CHF trio. For the entire out-of-sample period from September 13, 1993 to April 2, 1997 (910 observations), the columns under each correlation heading report the mean forecast errors (MFE), the root-mean-squared forecast errors (RMSFE), and the Diebold-Mariano test statistic (D\&M Test) for the null hypothesis of no difference in the forecast accuracy under the root-mean-squared loss function. MFE and RMSFE are defined as

$$
\operatorname{MFE}=\frac{1}{\mathrm{~N}} \sum_{\mathrm{t}=1}^{\mathrm{N}}\left(\rho(\bullet)_{\mathrm{t}, \mathrm{T}}-\hat{\rho}_{\mathrm{m}}(\bullet)_{\mathrm{t}, \mathrm{T}}\right) \text {, and RMSFE }=\sqrt{\frac{1}{\mathrm{~N}} \sum_{\mathrm{t}=1}^{\mathrm{N}}\left(\rho(\bullet)_{\mathrm{t}, \mathrm{T}}-\hat{\rho}_{\mathrm{mt}}(\bullet)_{\mathrm{t}, \mathrm{T}}\right)^{2}}
$$

respectively, where $\rho(\bullet)_{\mathrm{t}, \mathrm{T}}$ denotes the realized correlation and $\hat{\rho}_{\mathrm{m}}(\bullet)_{\mathrm{t}, \mathrm{T}}$ denotes the correlation forecast according to model m. The statistical significance of the MFEs is assessed by running regressions of the forecast errors on a constant; the standard errors of the estimated parameters are corrected for the induced heteroskedasticity and autocorrelation using the Newey and West (1987) procedure. The minimum RMSFE value in each column is marked in bold.

\begin{tabular}{|c|c|c|c|c|c|c|c|c|c|}
\hline \multirow[b]{2}{*}{ Forecast Method } & \multicolumn{3}{|c|}{$\rho\left(\varepsilon_{\mathrm{DEM} / \mathrm{USD}}, \varepsilon_{\mathrm{CHF} / \mathrm{USD}}\right)_{\mathrm{t}, \mathrm{T}}$} & \multicolumn{3}{|c|}{$\rho\left(\varepsilon_{\mathrm{USD} / \mathrm{DEM}}, \varepsilon_{\mathrm{CHF} / \mathrm{DEM}}\right)_{\mathrm{t}, \mathrm{T}}$} & \multicolumn{3}{|c|}{$\rho\left(\varepsilon_{\mathrm{USD} / \mathrm{CHF}}, \varepsilon_{\mathrm{DEM} / \mathrm{CHF}}\right)_{\mathrm{t}, \mathrm{T}}$} \\
\hline & MFE & RMSFE & $\underline{D} \& \mathrm{M}$ Test & $\underline{\mathrm{MFE}}$ & RMSFE & D\&M Test & MFE & RMSFE & D\&M Test \\
\hline Implied & $0.013 * *$ & 0.038 & - & $-0.266^{* *}$ & 0.348 & $2.43 * *$ & $\overline{0.194} * *$ & 0.251 & $3.57 * *$ \\
\hline H(20 days $)$ & -0.001 & 0.044 & 1.12 & -0.038 & 0.315 & $4.41 * *$ & 0.045 & 0.252 & $2.55 * *$ \\
\hline H(60 days $)$ & -0.002 & 0.044 & 0.94 & -0.025 & 0.257 & 1.11 & 0.028 & 0.200 & 1.50 \\
\hline H(120 days $)$ & -0.004 & 0.047 & 1.20 & -0.021 & 0.246 & 0.92 & 0.025 & 0.175 & 1.63 \\
\hline EWMA (0.94) & -0.002 & 0.039 & 0.18 & -0.029 & 0.260 & 1.39 & 0.033 & 0.206 & $1.73 *$ \\
\hline EWMA (0.97) & -0.003 & 0.040 & 0.33 & -0.025 & 0.239 & 0.45 & 0.028 & 0.183 & 1.26 \\
\hline EWMA (0.99) & -0.009 & 0.041 & 0.76 & -0.030 & 0.231 & - & 0.039 & 0.156 & - \\
\hline GARCH & -0.004 & 0.041 & 0.71 & $-0.113 * *$ & 0.267 & 1.20 & $0.098 * *$ & 0.167 & 0.78 \\
\hline
\end{tabular}

** Indicates statistical significance at the 1 percent level.

* Indicates statistical significance at the 5 percent level. 


\section{Partial Optimality Regressions for the One-Month Correlations in the USD/DEM/JPY Currency Trio}

This panel presents the results of the partial optimality regressions for the one-month correlation forecasts for the USD/DEM/JPY currency trio. For the entire out-of-sample period from October 2, 1990 through April 2,1997 (1679 observations), the columns under each correlation heading report the estimated coefficients and $\mathrm{R}^{2} \mathrm{~s}$ for the partial optimality regressions, which regress the realized correlations, denoted $\rho(\bullet)_{\mathrm{t}, \mathrm{T}}$, on the correlation forecast from model $\mathrm{m}$, denoted $\hat{\rho}_{\mathrm{m}}(\bullet)_{\mathrm{t}, \mathrm{T}}$; i.e., $\rho(\bullet)_{\mathrm{t}, \mathrm{T}}=\mathrm{a}+\mathrm{b} \hat{\rho}_{\mathrm{m}}(\bullet)_{\mathrm{t}, \mathrm{T}}+\mathrm{v}_{\mathrm{m}, \mathrm{t}^{\bullet}}$. Since we use overlapping periods, Newey and West (1987) standard errors that correct for the induced heteroskedasticity and autocorrelation are used.

\begin{tabular}{|c|c|c|c|c|c|c|c|c|c|}
\hline \multirow[b]{2}{*}{ Forecast Method } & \multicolumn{3}{|c|}{$\rho\left(\varepsilon_{\mathrm{DEM} / \mathrm{USD}}, \varepsilon_{\mathrm{JPY} / \mathrm{USD}}\right)_{\mathrm{t}, \mathrm{T}}$} & \multicolumn{3}{|c|}{$\rho\left(\varepsilon_{\mathrm{USD} / \mathrm{DEM}}, \varepsilon_{\mathrm{JPY} / \mathrm{DEM}}\right)_{\mathrm{t}, \mathrm{T}}$} & \multicolumn{3}{|c|}{$\rho\left(\varepsilon_{\mathrm{USD} / \mathrm{JPY}}, \varepsilon_{\mathrm{DEM} / \mathrm{JPY}}\right)_{\mathrm{t}, \mathrm{T}}$} \\
\hline & $\underline{\mathrm{a}}$ & $\underline{\mathrm{b}}$ & $\underline{\mathrm{R}^{2}}$ & $\underline{\mathrm{a}}$ & $\underline{\mathrm{b}}$ & $\underline{\mathrm{R}^{2}}$ & $\underline{\mathrm{a}}$ & $\underline{\mathrm{b}}$ & $\underline{\mathrm{R}^{2}}$ \\
\hline Implied & $0.195 * *$ & $0.741^{`}$ & 0.18 & -0.067 & $1.084^{\ddagger}$ & 0.39 & -0.122 & 1.112 & 0.37 \\
\hline H(20 days) & $0.392 * *$ & $0.367^{\star “}$ & 0.15 & $0.229 * *$ & $0.544^{\prime “}$ & 0.31 & $0.120 * *$ & $0.590^{\star}$ & 0.36 \\
\hline H(60 days) & $0.297 * *$ & $0.532^{،}$ & 0.22 & $0.169 * *$ & $0.652^{“}$ & 0.29 & $0.061 * *$ & $0.727^{،}$ & 0.39 \\
\hline H(120 days) & $0.304 * *$ & $0.529^{“}$ & 0.20 & $0.190 * *$ & $0.604^{“}$ & 0.19 & $0.054 * *$ & $0.714^{،}$ & 0.32 \\
\hline EWMA (0.94) & $0.302 * *$ & $0.519 “$ & 0.24 & $0.149 * *$ & $0.697 “$ & 0.40 & $0.075^{*}$ & $0.708 “$ & 0.43 \\
\hline EWMA (0.97) & $0.257 * *$ & $0.600 “$ & 0.26 & $0.110^{* *}$ & $0.767 “$ & 0.37 & 0.034 & $0.794 “$ & 0.43 \\
\hline EWMA (0.99) & $0.302 * *$ & $0.537^{،}$ & 0.15 & $0.089^{*}$ & $0.806^{6}$ & 0.26 & -0.005 & 0.826 & 0.26 \\
\hline GARCH & $0.206^{* *}$ & 0.679 & 0.27 & 0.058 & $0.909^{\ddagger}$ & 0.36 & -0.040 & $1.073^{\ddagger}$ & 0.40 \\
\hline
\end{tabular}

** indicates that $a$ is significantly different from zero at the 1 percent level, given the Newey and West (1987) standard errors.

* indicates that $a$ is significantly different from zero at the 5 percent level, given the Newey and West (1987) standard errors.

" indicates that $b$ is significantly different from one at the 1 percent level, given the Newey and West (1987) standard errors.

" indicates that $b$ is significantly different from one at the 5 percent level, given the Newey and West (1987) standard errors.

* indicates that the Wald-test for joint hypothesis $a=0$ and $b=1$ can not be rejected at the 1 percent level.

indicates that the Wald-test for joint hypothesis $a=0$ and $b=1$ can not be rejected at the 5 percent level. 
Table 4, Panel B.

\section{Partial Optimality Regressions for the Three-Month Correlations in the USD/DEM/JPY Currency Trio}

This panel presents the results of the partial optimality regressions for the three-month correlation forecasts for the USD/DEM/JPY currency trio. For the entire out-of-sample period from October 2, 1990 through April 2,1997 (1679 observations), the columns under each correlation heading report the estimated coefficients and $\mathrm{R}^{2} \mathrm{~s}$ for the partial optimality regressions, which regress the realized correlations, denoted $\rho(\bullet)_{\mathrm{t}, \mathrm{T}}$, on the correlation forecast from model $\mathrm{m}$, denoted $\hat{\rho}_{\mathrm{m}}(\bullet)_{\mathrm{t}, \mathrm{T}}$; i.e., $\rho(\bullet)_{\mathrm{t}, \mathrm{T}}=\mathrm{a}+\mathrm{b} \hat{\rho}_{\mathrm{m}}(\bullet)_{\mathrm{t}, \mathrm{T}}+\mathrm{v}_{\mathrm{m}, \mathrm{t}^{\bullet}}$. Since we use overlapping periods, Newey and West (1987) standard errors that correct for the induced heteroskedasticity and autocorrelation are used.

\begin{tabular}{|c|c|c|c|c|c|c|c|c|c|}
\hline \multirow[b]{2}{*}{$\underline{\text { Forecast Method }}$} & \multicolumn{3}{|c|}{$\rho\left(\varepsilon_{\mathrm{DEM} / \mathrm{USD}}, \varepsilon_{\mathrm{JPY} / \mathrm{USD}}\right)_{\mathrm{t}, \mathrm{T}}$} & \multicolumn{3}{|c|}{$\rho\left(\varepsilon_{\mathrm{USD} / \mathrm{DEM}}, \varepsilon_{\mathrm{JPY} / \mathrm{DEM}}\right)_{\mathrm{t}, \mathrm{T}}$} & \multicolumn{3}{|c|}{$\rho\left(\varepsilon_{\mathrm{USD} / \mathrm{JPY}}, \varepsilon_{\mathrm{DEM} / \mathrm{JPY}}\right)_{\mathrm{t}, \mathrm{T}}$} \\
\hline & $\underline{\mathrm{a}}$ & $\underline{b}$ & $\underline{\mathrm{R}^{2}}$ & $\underline{\mathrm{a}}$ & $\underline{b}$ & $\underline{\mathrm{R}^{2}}$ & $\underline{\mathrm{a}}$ & $\underline{b}$ & $\underline{\mathrm{R}^{2}}$ \\
\hline Implied & 0.067 & 0.946 & 0.25 & 0.018 & $0.952^{\ddagger}$ & 0.36 & -0.052 & 0.950 & 0.25 \\
\hline H(20 days) & $0.372 * *$ & $0.378^{\prime}$ & 0.34 & $0.314 * *$ & $0.392^{\prime}$ & 0.25 & $0.195 * *$ & $0.426^{\prime \prime}$ & 0.28 \\
\hline H(60 days) & $0.268 * *$ & $0.561^{“ 6}$ & 0.27 & $0.273 * *$ & $0.465^{\prime}$ & 0.22 & $0.140 * *$ & $0.561^{“}$ & 0.33 \\
\hline H(120 days $)$ & $0.294 * *$ & $0.527^{\star}$ & 0.18 & $0.287 * *$ & $0.433^{\prime \prime}$ & 0.15 & $0.152 * *$ & $0.500^{“}$ & 0.23 \\
\hline EWMA (0.94) & $0.283 * *$ & $0.530^{“}$ & 0.34 & $0.255^{* *}$ & $0.504^{“ “}$ & 0.31 & $0.168 * *$ & $0.524^{“ “}$ & 0.34 \\
\hline EWMA (0.97) & $0.238 * *$ & $0.612 “$ & 0.37 & $0.226 * *$ & $0.555^{\prime}$ & 0.28 & $0.128 * *$ & $0.588^{\prime}$ & 0.34 \\
\hline EWMA (0.99) & $0.310 * *$ & $0.504^{\prime}$ & 0.17 & $0.202 * *$ & $0.602^{\prime}$ & 0.21 & $0.136 * *$ & $0.509^{“}$ & 0.14 \\
\hline GARCH & $0.158 * *$ & $0.731^{\prime \prime}$ & 0.38 & $0.242 *$ & $0.566^{`}$ & 0.13 & -0.008 & $1.060^{\ddagger}$ & 0.29 \\
\hline
\end{tabular}

** indicates that $a$ is significantly different from zero at the 1 percent level, given the Newey and West (1987) standard errors.

* indicates that $a$ is significantly different from zero at the 5 percent level, given the Newey and West (1987) standard errors.

“ indicates that $b$ is significantly different from one at the 1 percent level, given the Newey and West (1987) standard errors.

- indicates that $b$ is significantly different from one at the 5 percent level, given the Newey and West (1987) standard errors.

$¥$ indicates that the Wald-test for joint hypothesis $a=0$ and $b=1$ can not be rejected at the 1 percent level. 


\section{Table 4, Panel C. \\ Partial Optimality Regressions for the One-Month Correlations in the USD/DEM/CHF Currency Trio}

This panel presents the results of the partial optimality regressions for the one-month correlation forecasts for the USD/DEM/CHF currency trio. For the entire out-of-sample period from September 13, 1993 through April 2, 1997 (910 daily observations), the columns under each correlation heading report the estimated coefficients and $\mathrm{R}^{2} \mathrm{~s}$ for the partial optimality regressions, which regress the realized correlations, denoted $\rho(\bullet)_{\mathrm{t}, \mathrm{T}}$, on the correlation forecast from model $\mathrm{m}$, denoted $\hat{\rho}_{\mathrm{m}}(\bullet)_{\mathrm{t}, \mathrm{T}}$; i.e., $\rho(\bullet)_{\mathrm{t}, \mathrm{T}}=\mathrm{a}+\mathrm{b} \hat{\rho}_{\mathrm{m}}(\bullet)_{\mathrm{t}, \mathrm{T}}+\mathrm{v}_{\mathrm{m}, \mathrm{t}^{\bullet}}$. Since we use overlapping periods, Newey and West (1987) standard errors that correct for the induced heteroskedasticity and autocorrelation are used.

\begin{tabular}{|c|c|c|c|c|c|c|c|c|c|}
\hline \multirow[b]{2}{*}{ Forecast Method } & \multicolumn{3}{|c|}{$\rho\left(\varepsilon_{\mathrm{DEM} / \mathrm{USD}}, \varepsilon_{\mathrm{CHF} / \mathrm{USD}}\right)_{\mathrm{t}, \mathrm{T}}$} & \multicolumn{3}{|c|}{$\rho\left(\varepsilon_{\mathrm{USD} / \mathrm{DEM}}, \varepsilon_{\mathrm{CHF} / \mathrm{DEM}}\right)_{\mathrm{t}, \mathrm{T}}$} & \multicolumn{3}{|c|}{$\rho\left(\varepsilon_{\mathrm{USD} / \mathrm{CHF}}, \varepsilon_{\mathrm{DEM} / \mathrm{CHF}}\right)_{\mathrm{t}, \mathrm{T}}$} \\
\hline & $\underline{\mathrm{a}}$ & $\underline{\mathrm{b}}$ & $\underline{\mathrm{R}^{2}}$ & $\underline{\mathrm{a}}$ & $\underline{\mathrm{b}}$ & $\underline{\mathrm{R}^{2}}$ & $\underline{\mathrm{a}}$ & $\underline{\mathrm{b}}$ & $\underline{\mathrm{R}^{2}}$ \\
\hline Implied & $0.206 * *$ & $0.793 “$ & 0.37 & $-0.240 * *$ & $0.633^{\circ}$ & 0.09 & $0.392 * *$ & $0.420 “$ & 0.06 \\
\hline H(20 days) & $0.354 * *$ & $0.619^{“}$ & 0.40 & $-0.169 * *$ & $0.357^{\star}$ & 0.14 & $0.408 * *$ & $0.290^{“}$ & 0.11 \\
\hline H (60 days) & $0.329 * *$ & $0.645^{\prime}$ & 0.34 & $-0.135^{* *}$ & $0.474 “$ & 0.15 & $0.385 * *$ & $0.322^{\prime}$ & 0.07 \\
\hline H (120 days) & $0.474 * *$ & $0.489 “$ & 0.15 & $-0.139 * *$ & $0.456^{\prime \prime}$ & 0.12 & $0.418 * *$ & $0.263^{\prime \prime}$ & 0.03 \\
\hline EWMA (0.94) & $0.254 * *$ & $0.726 “$ & 0.48 & $-0.137 * *$ & $0.474^{\prime “}$ & 0.18 & $0.353 * *$ & $0.382^{\prime}$ & 0.12 \\
\hline EWMA (0.97) & $0.225^{* *}$ & $0.756^{\prime \prime}$ & 0.41 & $-0.118 * *$ & $0.545^{\prime}$ & 0.19 & $0.326 * *$ & $0.427^{\prime}$ “ & 0.10 \\
\hline EWMA (0.99) & $0.217 * *$ & $0.759 “$ & 0.21 & $-0.113^{* *}$ & $0.581^{“}$ & 0.14 & $0.286 * *$ & $0.508 “$ & 0.06 \\
\hline GARCH & $-0.687 *$ & $1.730^{`}$ & 0.17 & $-0.151 * *$ & $0.580 “$ & 0.12 & $0.173 *$ & 0.770 & 0.20 \\
\hline
\end{tabular}

** indicates that $a$ is significantly different from zero at the 1 percent level, given the Newey and West (1987) standard errors.

* indicates that $a$ is significantly different from zero at the 5 percent level, given the Newey and West (1987) standard errors.

" indicates that $b$ is significantly different from one at the 1 percent level, given the Newey and West (1987) standard errors.

- indicates that $b$ is significantly different from one at the 5 percent level, given the Newey and West (1987) standard errors.

$\ddagger$ indicates that the Wald-test for joint hypothesis $a=0$ and $b=1$ can not be rejected at the 1 percent level. 
Table 4, Panel D.

\section{Partial Optimality Regressions for the Three-Month Correlations in the USD/DEM/CHF Currency Trio}

This panel presents the results of the partial optimality regressions for the three-month correlation forecasts for the USD/DEM/CHF currency trio. For the entire out-of-sample period from September 13, 1993 through April 2, 1997 (910 daily observations), the columns under each correlation heading report the estimated coefficients and $\mathrm{R}^{2} \mathrm{~s}$ for the partial optimality regressions, which regress the realized correlations, denoted $\rho(\bullet)_{\mathrm{t}, \mathrm{T}}$, on the correlation forecast from model $\mathrm{m}$, denoted $\hat{\rho}_{\mathrm{m}}(\bullet)_{\mathrm{t}, \mathrm{T}}$; i.e., $\rho(\bullet)_{\mathrm{t}, \mathrm{T}}=\mathrm{a}+\mathrm{b} \hat{\rho}_{\mathrm{m}}(\bullet)_{\mathrm{t}, \mathrm{T}}+\mathrm{v}_{\mathrm{m}, \mathrm{t}^{\bullet}}$. Since we use overlapping periods, Newey and West (1987) standard errors that correct for the induced heteroskedasticity and autocorrelation are used.

\begin{tabular}{|c|c|c|c|c|c|c|c|c|c|}
\hline \multirow[b]{2}{*}{ Forecast Method } & \multicolumn{3}{|c|}{$\rho\left(\varepsilon_{\text {DEM/USD }}, \varepsilon_{\mathrm{CHF} / \mathrm{USD}}\right)_{\mathrm{t}, \mathrm{T}}$} & \multicolumn{3}{|c|}{$\rho\left(\varepsilon_{\mathrm{USD} / \mathrm{DEM}}, \varepsilon_{\mathrm{CHF} / \mathrm{DEM}}\right)_{\mathrm{t}, \mathrm{T}}$} & \multicolumn{3}{|c|}{$\rho\left(\varepsilon_{\mathrm{USD} / \mathrm{CHF}}, \varepsilon_{\mathrm{DEM} / \mathrm{CHF}}\right)_{\mathrm{t}, \mathrm{T}}$} \\
\hline & $\underline{\mathrm{a}}$ & $\underline{\mathrm{b}}$ & $\underline{\mathrm{R}^{2}}$ & $\underline{\mathrm{a}}$ & $\underline{\mathrm{b}}$ & $\underline{\mathrm{R}^{2}}$ & $\underline{\mathrm{a}}$ & $\underline{\mathrm{b}}$ & $\underline{\mathrm{R}^{2}}$ \\
\hline Implied & $0.172 *$ & $0.827^{`}$ & 0.27 & $-0.270 * *$ & $0.348 “$ & 0.04 & $0.551 * *$ & $0.102 “$ & 0.01 \\
\hline H(20 days) & $0.496^{* *}$ & $0.467 “$ & 0.27 & $-0.217 * *$ & $0.237^{\prime}$ & 0.12 & $0.532 * *$ & $0.108 “$ & 0.04 \\
\hline H (60 days) & $0.520 * *$ & $0.440^{،}$ & 0.19 & $-0.187 * *$ & $0.344^{\prime “}$ & 0.15 & $0.526 * *$ & $0.116^{6 "}$ & 0.02 \\
\hline H(120 days) & $0.626 * *$ & $0.326^{\prime}$ & 0.08 & $-0.183 * *$ & $0.356^{“}$ & 0.13 & $0.514 * *$ & $0.136^{6}$ & 0.02 \\
\hline EWMA (0.94) & $0.411 * *$ & $0.557^{\prime}$ & 0.33 & $-0.187 * *$ & $0.353^{“}$ & 0.18 & $0.504 * *$ & $0.155^{\prime \prime}$ & 0.05 \\
\hline EWMA (0.97) & $0.415^{* *}$ & $0.552^{،}$ & 0.26 & $-0.172 * *$ & $0.406 “$ & 0.19 & $0.496^{* *}$ & $0.168^{\prime \prime}$ & 0.04 \\
\hline EWMA (0.99) & $0.397 * *$ & 0.568 “ & 0.14 & $-0.174 * *$ & $0.406^{6}$ & 0.11 & $0.469 * *$ & $0.219^{“}$ & 0.03 \\
\hline GARCH & 0.170 & $0.814^{\ddagger}$ & 0.04 & $-0.235 * *$ & $0.237 * *$ & 0.03 & $0.388 * *$ & $0.414^{\prime ،}$ & 0.10 \\
\hline
\end{tabular}

** indicates that $a$ is significantly different from zero at the 1 percent level, given the Newey and West (1987) standard errors.

* indicates that $a$ is significantly different from zero at the 5 percent level, given the Newey and West (1987) standard errors.

" indicates that $b$ is significantly different from one at the 1 percent level, given the Newey and West (1987) standard errors.

- indicates that $b$ is significantly different from one at the 5 percent level, given the Newey and West (1987) standard errors.

* indicates that the Wald-test for joint hypothesis $a=0$ and $b=1$ can not be rejected at the 1 percent level. 


\section{Table 5, Panel A. \\ Encompassing Regressions for the One-Month Correlations in the USD/DEM/JPY Currency Trio}

This table presents the results of the encompassing regressions of realized correlations on a constant and four correlation forecasts; i.e.,

$$
\rho(\bullet)_{\mathrm{t}, 1}=\gamma_{0}+\sum_{\mathrm{j}=1}^{4} \gamma_{\mathrm{j}} \hat{\rho}_{\mathrm{j}}(\bullet)_{\mathrm{t}, 1}+\mathrm{v}_{\mathrm{t}},
$$

where $\rho(\bullet)_{\mathrm{t}, 1}$ denotes the realized correlation for over a horizon of 1 month and $\hat{\rho}_{\mathrm{m}}(\bullet)_{\mathrm{t}, 1}$ denotes the corresponding correlation forecast according to method $\mathrm{m}$. The four forecasts used are implied correlation, GARCH-based correlation, and the historical and EWMA correlation with the highest $\mathrm{R}^{2} \mathrm{~s}$ in the partial optimality regressions. The observation period is the entire, out-of-sample period of October 2, 1990 through April 2,1997 (1679 daily observations). The standard errors are corrected for the induced heteroskedasticity and autocorrelation using the Newey and West (1987) procedure. The bottom rows of the panel contain the Wald test results for the null hypothesis in parentheses. $\chi^{2}($ Implied $=0$ ) tests the restriction that the coefficient on implied correlation equals zero; $\chi^{2}($ Other $=0)$ tests the restriction that the coefficients on all the time-series forecasts are zero; and $\chi^{2}(\mathrm{GARCH}=0)$ tests the restriction that the coefficient on the forecast from the bivariate GARCH model is zero.

\begin{tabular}{|c|c|c|c|}
\hline & $\rho\left(\varepsilon_{\mathrm{DEM} / \mathrm{USD}}, \varepsilon_{\mathrm{JPY} / \mathrm{USD}}\right)_{\mathrm{t}, 1}$ & $\rho\left(\varepsilon_{\mathrm{USD} / \mathrm{DEM}}, \varepsilon_{\mathrm{JPY} / \mathrm{DEM}}\right)_{\mathrm{t}, 1}$ & $\rho\left(\varepsilon_{\mathrm{USD} / \mathrm{JPY}}, \varepsilon_{\mathrm{DEM} / \mathrm{JPY}}\right)_{\mathrm{t}, 1}$ \\
\hline$\gamma_{0}$ & $0.172 * *$ & -0.019 & -0.021 \\
\hline \multicolumn{4}{|c|}{ Forecast Methods $\left(\gamma_{j}{ }^{6} s\right)$} \\
\hline Implied & 0.111 & $0.494 * *$ & $0.315 *$ \\
\hline H(20 days) & - & -0.176 & - \\
\hline H(60 days) & 0.036 & - & 0.110 \\
\hline H(120 days) & - & - & - \\
\hline EWMA (0.94) & - & $0.488 *$ & 0.362 \\
\hline EWMA $(0.97)$ & 0.146 & - & - \\
\hline EWMA (0.99) & - & - & - \\
\hline GARCH & $0.450 * *$ & 0.210 & 0.160 \\
\hline $\mathrm{R}^{2}$ & 0.29 & 0.43 & 0.45 \\
\hline$\chi^{2}($ Implied $=0)$ & 0.8 & $14.9 * *$ & $4.3 *$ \\
\hline$\chi^{2}($ Other $=0)$ & $66.1 * *$ & $21.9 * *$ & $39.3 * *$ \\
\hline$\chi^{2}(\mathrm{GARCH}=0)$ & $7.5^{* *}$ & 0.6 & 0.3 \\
\hline
\end{tabular}

** Indicates statistical significance at the 1 percent level, given the Newey and West (1987) standard errors.

* Indicates statistical significance at the 5 percent level, given the Newey and West (1987) standard errors. 


\section{Table 5, Panel B. \\ Encompassing Regressions for the Three-Month Correlations in the USD/DEM/JPY Currency Trio}

This table presents the results of the encompassing regressions of realized correlations on a constant and four correlation forecasts; i.e.,

$$
\rho(\bullet)_{\mathrm{t}, 3}=\gamma_{0}+\sum_{\mathrm{j}=1}^{4} \gamma_{\mathrm{j}} \hat{\rho}_{\mathrm{j}}(\bullet)_{\mathrm{t}, 3}+\mathrm{v}_{\mathrm{t}},
$$

where $\rho(\bullet)_{\mathrm{t}, 3}$ denotes the realized correlation for over a horizon of 3 months and $\hat{\rho}_{\mathrm{m}}(\bullet)_{\mathrm{t}, 3}$ denotes the corresponding correlation forecast according to method $\mathrm{m}$. The four forecasts used are implied correlation, GARCH-based correlation, and the historical and EWMA correlation with the highest $\mathrm{R}^{2} \mathrm{~s}$ in the partial optimality regressions. The observation period is the entire, out-of-sample period of October 2, 1990 through April 2,1997 (1679 daily observations). The standard errors are corrected for the induced heteroskedasticity and autocorrelation using the Newey and West (1987) procedure. The bottom rows of the panel contain the Wald test results for the null hypothesis in parentheses. $\chi^{2}($ Implied $=0$ ) tests the restriction that the coefficient on implied correlation equals zero; $\chi^{2}($ Other $=0)$ tests the restriction that the coefficients on all the time-series forecasts are zero; and $\chi^{2}(\mathrm{GARCH}=0)$ tests the restriction that the coefficient on the forecast from the bivariate GARCH model is zero.

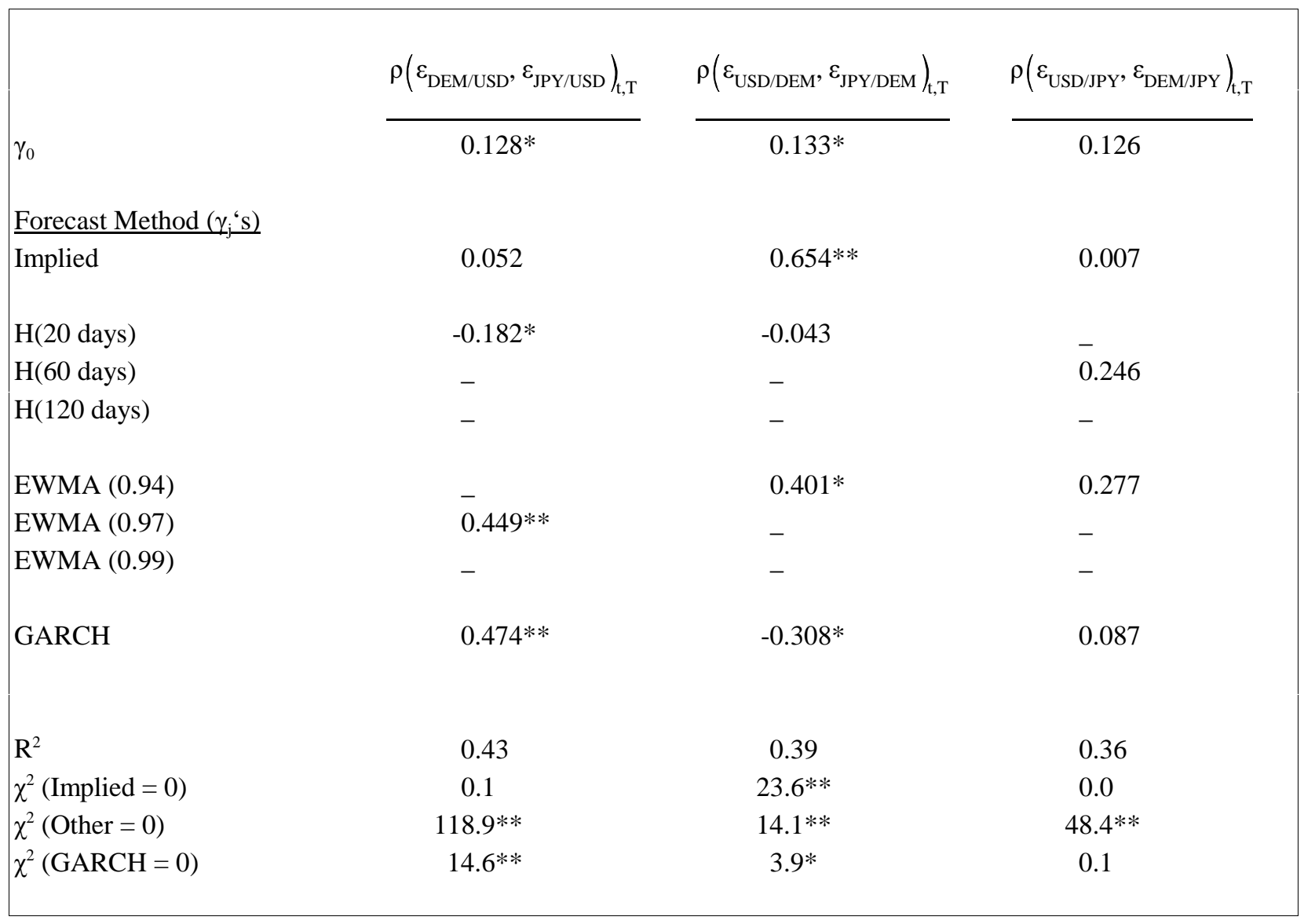

** Indicates statistical significance at the 1 percent level, given the Newey and West (1987) standard errors.

* Indicates statistical significance at the 5 percent level, given the Newey and West (1987) standard errors. 


\section{Table 5, Panel C. \\ Encompassing Regressions for the One-Month Correlations in the USD/DEM/CHF Currency Trio}

This table presents the results of the encompassing regressions of realized correlations on a constant and four correlation forecasts; i.e.,

$$
\rho(\bullet)_{\mathrm{t}, 1}=\gamma_{0}+\sum_{\mathrm{j}=1}^{4} \gamma_{\mathrm{j}} \hat{\rho}_{\mathrm{j}}(\bullet)_{\mathrm{t}, 1}+\mathrm{v}_{\mathrm{t}},
$$

where $\rho(\bullet)_{\mathrm{t}, 1}$ denotes the realized correlation for over a horizon of 1 month and $\hat{\rho}_{\mathrm{m}}(\bullet)_{\mathrm{t}, 1}$ denotes the corresponding correlation forecast according to method $\mathrm{m}$. The four forecasts used are implied correlation, GARCH-based correlation, and the historical and EWMA correlation with the highest $\mathrm{R}^{2} \mathrm{~s}$ in the partial optimality regressions. The observation period is the entire, out-of-sample period of September 13, 1993 through April 2,1997 (910 daily observations). The standard errors are corrected for the induced heteroskedasticity and autocorrelation using the Newey and West (1987) procedure. The bottom rows of the panel contain the Wald test results for the null hypothesis in parentheses. $\chi^{2}($ Implied $=0$ ) tests the restriction that the coefficient on implied correlation equals zero; $\chi^{2}($ Other $=0)$ tests the restriction that the coefficients on all the time-series forecasts are zero; and $\chi^{2}(\mathrm{GARCH}=0)$ tests the restriction that the coefficient on the forecast from the bivariate GARCH model is zero.

\begin{tabular}{|c|c|c|c|}
\hline & $\rho\left(\varepsilon_{\text {DEM/USD }}, \varepsilon_{\mathrm{CHF} / \mathrm{USD}}\right)_{\mathrm{t}, \mathrm{T}}$ & $\rho\left(\varepsilon_{\mathrm{USD} / \mathrm{DEM}}, \varepsilon_{\mathrm{CHF} / \mathrm{DEM}}\right)_{\mathrm{t}, \mathrm{T}}$ & $\rho\left(\varepsilon_{\mathrm{USD} / \mathrm{CHF}}, \varepsilon_{\mathrm{DEM} / \mathrm{CHF}}\right)_{\mathrm{t}, \mathrm{T}}$ \\
\hline$\gamma_{0}$ & 0.187 & $-0.127 * *$ & $0.189 * *$ \\
\hline \multicolumn{4}{|c|}{ Forecast Method $\left(\gamma_{j}^{\prime} s\right)$} \\
\hline Implied & $0.289 * *$ & 0.081 & -0.199 \\
\hline H(20 days $)$ & -0.041 & - & 0.124 \\
\hline H(60 days $)$ & - & -0.170 & - \\
\hline H(120 days) & - & - & - \\
\hline EWMA (0.94) & $0.613 * *$ & - & -0.247 \\
\hline EWMA (0.97) & - & $0.770 *$ & - \\
\hline EWMA (0.99) & - & - & - \\
\hline GARCH & 0.058 & -0.138 & $1.039 * *$ \\
\hline $\mathrm{R}^{2}$ & 0.50 & 0.20 & 0.21 \\
\hline$\chi^{2}($ Implied $=0)$ & $9.9 * *$ & 0.2 & 1.2 \\
\hline$\chi^{2}($ Other $=0)$ & $42.0 * *$ & $28.5 * *$ & $27.2 * *$ \\
\hline$\chi^{2}(\mathrm{GARCH}=0)$ & 0.1 & 0.3 & $14.5 * *$ \\
\hline
\end{tabular}

** Indicates statistical significance at the 1 percent level, given the Newey and West (1987) standard errors.

* Indicates statistical significance at the 5 percent level, given the Newey and West (1987) standard errors. 


\section{Table 5, Panel D. \\ Encompassing Regressions for the Three-Month Correlations in the USD/DEM/CHF Currency Trio}

This table presents the results of the encompassing regressions of realized correlations on a constant and four correlation forecasts; i.e.,

$$
\rho(\bullet)_{\mathrm{t}, 3}=\gamma_{0}+\sum_{\mathrm{j}=1}^{4} \gamma_{\mathrm{j}} \hat{\rho}_{\mathrm{j}}(\bullet)_{\mathrm{t}, 3}+\mathrm{v}_{\mathrm{t}},
$$

where $\rho(\bullet)_{\mathrm{t}, 3}$ denotes the realized correlation for over a horizon of 3 months and $\hat{\rho}_{\mathrm{m}}(\bullet)_{\mathrm{t}, 3}$ denotes the corresponding correlation forecast according to method $\mathrm{m}$. The four forecasts used are implied correlation, GARCH-based correlation, and the historical and EWMA correlation with the highest $\mathrm{R}^{2} \mathrm{~s}$ in the partial optimality regressions. The observation period is the entire, out-of-sample period of September 13, 1993 through April 2,1997 (910 daily observations). The standard errors are corrected for the induced heteroskedasticity and autocorrelation using the Newey and West (1987) procedure. The bottom rows of the panel contain the Wald test results for the null hypothesis in parentheses. $\chi^{2}($ Implied $=0$ ) tests the restriction that the coefficient on implied correlation equals zero; $\chi^{2}($ Other $=0)$ tests the restriction that the coefficients on all the time-series forecasts are zero; and $\chi^{2}(\mathrm{GARCH}=0)$ tests the restriction that the coefficient on the forecast from the bivariate GARCH model is zero.

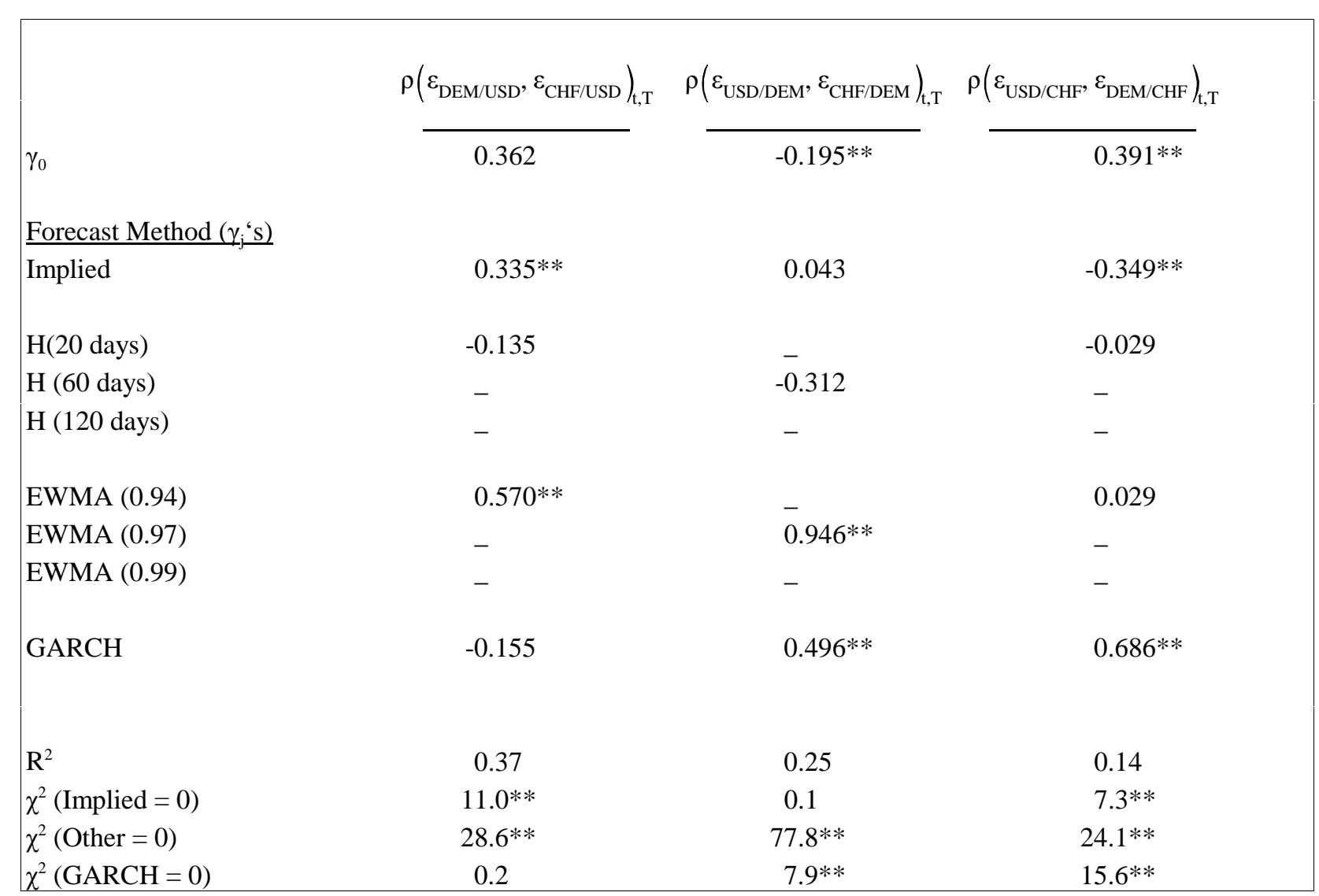

** Indicates statistical significance at the 1 percent level, given the Newey and West (1987) standard errors.

* Indicates statistical significance at the 5 percent level, given the Newey and West (1987) standard errors. 


\section{Table 6. \\ Encompassing Regressions for the One-Month Correlation between the DEM and the JPY measured in USD: Subsamples}

This table presents the results of the encompassing regressions of realized correlations on a constant and four correlation forecasts; i.e.,

$$
\rho(\bullet)_{\mathrm{t}, 1}=\gamma_{0}+\sum_{\mathrm{j}=1}^{4} \gamma_{\mathrm{j}} \hat{\rho}_{\mathrm{j}}(\bullet)_{\mathrm{t}, 1},
$$

where $\rho(\bullet)_{\mathrm{t}, 1}$ denotes the realized correlation for over a horizon of 1 month and $\hat{\rho}_{\mathrm{m}}(\bullet)_{\mathrm{t}, 1}$ denotes the corresponding correlation forecast according to method $\mathrm{m}$. The four forecasts used are implied correlation, GARCH-based correlation, and the historical and EWMA correlation with the highest $\mathrm{R}^{2} \mathrm{~s}$ in the partial optimality regressions. The observation period is the entire, out-of-sample period, but broken into eight non-overlapping subsamples of roughly 200 observations each. The standard errors are corrected for the induced heteroskedasticity and autocorrelation using the Newey and West (1987) procedure.

\begin{tabular}{|c|c|c|c|c|c|}
\hline$\gamma_{0}$ & $\gamma_{\text {Implied }}$ & $\gamma_{H(60)}$ & $\gamma_{\mathrm{E}(0.97)}$ & $\gamma_{\text {GARCH }}$ & $\mathbf{R}^{2}$ \\
\hline \multicolumn{6}{|c|}{ A. October 2, 1990 - July 8, 1991 (200 observations) } \\
\hline $0.471 * *$ & $0.507^{* *}$ & $0.692 * *$ & $-1.308 * *$ & $0.547 * *$ & 0.43 \\
\hline
\end{tabular}

B. July 9, 1991 - April 13, 1992 (200 observations)

\begin{tabular}{cccccc}
$0.897 * *$ & -0.124 & -0.624 & 0.425 & -0.047 & 0.05 \\
\hline \multicolumn{7}{c}{ C. April 14, 1992 - January 18, 1993 (200 observations) } \\
$0.893 * *$ & $0.349 * *$ & 0.736 & $-3.078 * *$ & $1.727 * *$ & 0.24 \\
\hline
\end{tabular}

D. January 19, 1993 - October 25, 1993 (200 observations)

\begin{tabular}{cccccc}
0.099 & $0.979 *$ & -0.578 & 0.046 & -0.030 & 0.10 \\
\hline \multicolumn{7}{c}{ E. October 26, 1993 - August 1, 1994 (200 observations) } \\
0.365 & -0.118 & -0.485 & $1.870^{*}$ & -0.763 & 0.51 \\
\hline
\end{tabular}

F. August 2, 1994 - May 9, 1995 (200 observations)

\begin{tabular}{cccccc}
$2.031 * *$ & -0.061 & $-1.249 * *$ & -0.670 & 0.188 & 0.43 \\
\hline G. May 10, 1995 - February 21, 1996 (200 observations) \\
0.529 & -0.429 & 0.086 & -0.046 & 0.645 & 0.15 \\
\hline
\end{tabular}

H. February 22, 1996 - April 2, 1997 (279 observations)

$\begin{array}{llllll}0.996 * * & -0.419 & -0.561 & 0.894 & -0.654 & 0.07\end{array}$

** Indicates statistical significance at the 1 percent level, given the Newey and West (1987) standard errors.

* Indicates statistical significance at the 5 percent level, given the Newey and West (1987) standard errors. 